\title{
Modelling and forecasting hourly electricity demand in West African countries
}

Omotola Adeoye ${ }^{1}$, Catalina Spataru.

UCL Energy Institute, University College London, United Kingdom.

\begin{abstract}
The Economic Community of West African States aims to achieve 100\% electrification rates by 2030 in all member countries. To achieve this ambitious target, electricity generation capacities need to be increased significantly. Forecasting hourly electricity demand is imperative for capacity planners in optimizing investment options and ensuring reliable electricity supply. However, modelling hourly electricity demand in developing countries can be a challenge due to paucity of historical demand data and methodological frameworks that adequately capture technology transitions and urban-rural communities. In this study, we address this gap by developing an hourly electricity demand model for 14 West African countries in the year 2016 and 2030.The model takes into accounts electrification rates, available household appliances, occupancy patterns of household members, type of day, available daylight hours and hourly weather conditions. Annual electricity demand in nonresidential sectors and electricity access rates in urban and rural households are forecasted using multiple regression analysis. We validated the developed model using actual 2016 monthly and annual electricity demand data. The results show the seasonal variations of electricity demand, with hourly electricity demand in dry seasons relatively higher than demand in wet seasons. The results also indicate that in 2030, electricity demand in the West African region is estimated to be five times its 2016 level. The methodology presented in this study can be applicable for modelling hourly electricity demand in developing countries that have scarce historical hourly demand data, a significant electricity supply-demand gap, and varying electricity access rates in urban and rural areas.
\end{abstract}

\section{Keywords}

Electricity demand modelling, West Africa, developing countries, residential demand, demand forecasting, hourly electricity demand.

\section{Nomenclature}

Symbols

Description (Unit)

$\mathrm{P}$

Electricity consumption (Watts)

$\mathrm{U}$

Probability of use of an appliance

$\mathrm{R}$

Power rating (Watts)

$\mathrm{O}$

\footnotetext{
${ }^{1}$ Corresponding author at Central House, 14 Upper Woburn Place, London, WC1H 0NN

Email address: omotola.adeoye.14@ucl.ac.uk

Phone number: +447462952106
} 
Appliance ownership rate (\%)

Electrified population

$q$

Air flow rate $\left(\mathrm{m}^{3} / \mathrm{s}\right)$

$\rho$

Air density $\left(\mathrm{kg} / \mathrm{m}^{3}\right)$

$h$

$\mathrm{H}$

Enthalpy $(\mathrm{kj} / \mathrm{kg})$

Relative humidity (\%)

$\mathrm{H} R$

Humidity ratio

C

Specific heat $\left(\mathrm{Kj} / \mathrm{kg}^{\circ} \mathrm{C}\right)$

$\mathrm{T}$

Temperature $\left({ }^{\circ} \mathrm{C}\right)$

$p$

Pressure $(\mathrm{Pa})$

$\mathrm{L}$

Artificial light (Lumens)

I

Lighting level (Lux)

A

$\mathrm{CU}$

Area $\left(\mathrm{m}^{2}\right)$

$\begin{array}{ll}\text { Lf } & \text { Coefficient of utilization } \\ \text { Le } & \text { Light loss factor } \\ & \text { Luminous Efficacy (Lumens/watts) }\end{array}$

E

Electricity demand (GWh)

$\mathrm{HC}$

Hourly Coefficient

\section{Introduction}

In West African countries ${ }^{1}$ approximately 171 million people have no access to electricity, with $18 \%$ of these people living in urban areas and $82 \%$ in rural areas [1]. On the other hand, those with access to electricity experience frequent unplanned power outages due to insufficient generation capacities [2,3]. With the concept of utilizing available energy resources in the region to benefit all countries and a mission to provide reliable and affordable electricity, the

\footnotetext{
${ }^{1}$ The West African countries referred to in this study are 14 out of the 15 members of the Economic Community of West African States (ECOWAS) who are members of the West African Power Pool. They include; Benin, Burkina Faso, Cote D’Ivoire, Gambia, Ghana, Guinea, Guinea Bissau, Liberia, Mali, Niger, Nigeria, Senegal, Sierra Leone and Togo
} 
West African Power Pool (WAPP) was created. WAPP set an ambitious goal to interconnect the power systems of all member countries into a single regional electricity market by 2025 , by developing generation and transmission infrastructures [3]. Furthermore, the Economic Community of West African States (ECOWAS) has set an ambitious target to achieve 100\% electrification rates in all member countries by 2030 [4]. Given that electricity supply and demand need to balance at all times to ensure a stable power system, forecasting demand and planning supply is of particular importance to increase electricity access in the region and provide reliable power supply. However, major challenges to electricity demand forecasting in developing countries include lack of quality data, and existing modelling methodologies that do not adequately capture the electricity supply-demand gap, transition to modern technologies, and urban-rural economic divide [5].

Due to the aforementioned challenges, there are limited studies that have developed methodologies for forecasting hourly and annual electricity demand in West African countries. Majority of these studies forecast only annual electricity demand based on projected GDP and population growth [6-13]. In order to capture some specific characteristics of the power sector in developing countries, some studies include other parameters in addition to macro-economic parameters. Examples include income elasticity of electricity consumption [11]; assumed electricity access rates $[7,11,13]$; tiers of electrification [10]; and existing unserved demand $[12,13]$.

There are currently several national and regional targets with plans to integrate large shares of renewable energy sources (RES) in the West African region. In order to capture the impact of the RES intermittency and assess the operational flexibility of the future power system, there is a need to model and forecast hourly electricity demand in a country. This study develops an hourly and annual electricity demand model for West African countries in the base year 2016 using a hybrid methodology. The hourly electricity demand in the residential sector of each country is modelled using a bottom-up methodology for the urban and rural households, while the non-residential sectors (industrial, commercial and services) are aggregated and modelled using a top-down methodology. We consider several economic, social, technical and weather factors when modelling the hourly electricity demand. These factors include projected GDP and population growth, electricity access rates, weather (temperature and humidity) conditions, time and type of day, unserved demand, household appliance ownership and economic activities in urban and rural households. We then validate the results from the model with the actual 2016 monthly and annual demand data, and proceed to forecast the hourly and annual electricity demand for each country in the year 2030 .

This study contributes to the growing literature on hourly electricity demand modelling in developing countries. Firstly, so far to our knowledge, this is the first study to take weather conditions in different parts of a country, and appliance ownership rates in urban and rural households into account when modelling hourly electricity demand for an entire year in developing countries. Secondly, with plans by the WAPP to create a single regional electricity market where generation companies bid to supply hourly electricity demand a day in advance, this study provides a 2030 hourly demand dataset for West African countries useful for shortterm unit commitment planning of power plants. Thirdly, while this study was focused on the development of a detailed hourly and annual West African electricity demand model, the methodology outlined in this paper can be applicable to other developing countries that have similar challenges in demand modelling, such as lack of quality data, electricity supply-demand gap, and urban-rural economic divide. 
The rest of the paper is structured as follow; Section 2 discusses literature on hourly electricity demand modelling. Section 3 presents a description of the model and the data used. Section 4 discusses the validation of the model and electricity demand results in 2016 and 2030. Section 5 summarizes the main conclusions and application of the study.

\section{Literature Review}

Numerous studies have modelled and forecasted hourly electricity demand for both developed and developing countries, on a country, regional and sector level. These studies have used several methodologies which has been reviewed in literature [14]. Total electricity demand for a country can be estimated by aggregating the electricity demand of individual sectors in the country, which are typically the residential, industrial, services and transport sectors [15].

Several studies have focused only on developing hourly demand models for specific sectors in a country. In comparison to the residential sector, there are fewer studies focused on the industrial, service and transport sector. The hourly electricity demand in residential households has been modelled for an entire year in Japan[16], United Kingdom [17], Finland [18], Brazil [19], Sweden [20], Australia [21], United States [22],Germany[23], and Denmark [24] . These models typically involve using behavioural, economic, social, technical and weather data to model the electricity demand of representative households and its members. The modelled demand in most studies can be further aggregated to represent the entire residential sector of a country. In Shimoda et al. [16], all the households in Osaka city, Japan were divided into 460 types of dwellings, and the electricity consumption for each type of dwelling was simulated based on appliance ownership and rating, weather data, dwelling insulation, and schedule of activities of household members estimated from a national Time Use (TU) survey. The stochastic model in Yao and Steemers [17] uses number of occupants, occupancy hours, daily electricity consumption of appliances, randomly generated occupancy scenarios and appliance usage to synthesize the hourly electricity demand profiles for $100 \mathrm{UK}$ households. The model in Paatero and Lund [18] first defines the appliances and their daily fluctuation trends, then the demand profile of each appliance in each household was simulated based on its consumption cycle obtained from previously measured data in Finland. Widén and Wäckelgård [20] developed a stochastic bottom-up model to synthesize the hourly electricity demand for a set of households in Sweden. The model takes into account TU survey data to generate activity patterns for each member of the household using a Markov chain model, these patterns are then converted into electricity demand. Similar to [20], Sandels et al. [25] used Markov chain model to synthesize activity patterns, however their model considers not only appliances but also domestic hot water and space heating when simulating the hourly electricity consumption for a number of households in Sweden.

On the other hand, other studies have focused on modelling and forecasting hourly electricity demands in non-residential sectors. Aman and Ping [26] used the MEAD model to forecast the hourly demand of the steel sector in Malaysia, with one year historical data used to define the seasonal, daily and hourly fluctuations in the sector. Pielow et al. [27] presented a regression model to generate the hourly electricity demand for the entire year in both the industrial and commercial sector of three cities in US. The model used four years historical hourly datasets and takes into account weather and calander variables. In examining the growth of electric vehicles in Iran's transportation sector, Sadri et al. [28] used EnergyPLAN simulation model to synthesize the hourly electricity demand in the sector up to 2025. Voulis et al. [29] used time, weather and building data from both Neatherlands and US as inputs data in the EnergyPlus modelling tool, in order to generate the hourly electricity demand of the service 
sector in Netherlands. Kipping and Trømborg [30] models the hourly electricity consumption of the service sector in Norway and takes into account temprature, type of day, building age and floor space, hourly meter and energy label data.

There are a number of studies that focused on modelling and forecasting hourly electricity demand for an entire year at an aggregated country level. Hainoun [31] used the Model for Analysis of Energy and Electricity Demand (MAED), previous weekly, daily and hourly electricity demand, to reconstruct and forecast hourly electricity demand in Syria's four sectors. Pina et al. [32] developed a high resolution TIMES model for Sao Miguel in order to model the hourly electricity demand for the island by using historical hourly electricity demand data for three types of days in the four season in a year, in each of the five sectors on the island. Andersen et al. [33] modelled and forecasted hourly electricity demand in Denmark up to 2030 using hourly metering data from 4500 customers representing different categories of customers in different sectors. Spataru and Barrett [34] developed a demand model that accounts for weather and social activity patterns in the residential, services, industrial and transport sectors at a distribution network level in United Kingdom. Bobmann and Staffell [35] used two models and historical hourly load curve data to forecast the hourly electricity load curves of the major economic sectors in Britain and Germany in 2050. Yukseltan et al. presented a linear model used to forecast hourly electricity demand in the residential and industrial sector of Turkey, by using hourly demand data from three consecutive previous years [36].

These aforementioned studies in literature use either previously recorded TU survey data and or available historical hourly electricity demand data for the entire year, which is a challenge for majority of the developing countries. Therefore, there are very few hourly electricity demand models for an entire year in developing countries. In Miketa and Merven [37], the hourly demand for each country in West Africa for the entire year up to 2030 was defined by three demand categories (urban, rural, and heavy industry), three seasons (pre-summer, summer and post-summer) in a year and three blocks (day-time, evening and night-time) of equal demand during the day. Adeoye and Spataru [38] forecast 2025 hourly demand for each country in West Africa by linearly scaling up the 2009 hourly demand profiles developed in Miketa and Merven [37] to the projected annual electricity demand and peak demand in the WAPP master plan [12] . Ouedraogo [39] modelled the hourly demand profile for sub-Sahara African countries up to 2040 using the Long-range Energy Alternative Planning (LEAP) model, with residential sector demand forecasted using projected household size, population, electrification rate and electricity intensity, while the non-residential sectors (agriculture, industries and services) were forecasted using only projected electricity intensity and number of customers.

Unlike the previous studies that modelled the hourly electricity demand in West African countries, this study takes into account several economic, social, technical, weather and calendar factors when modelling the hourly demand for the residential and non-residential sectors in West African countries. The developed model also captures the change in ownership rate and transition to modern household appliances in both urban and rural households. Given the lack of TU survey data in West African countries, our model generates synthetic TU data for urban and rural households in the residential sector based on the type of days in the year, hours spent on income generating activities, and average appliance operation times. In this study, we validate the developed model against actual monthly and annual electricity demand in 2016. 


\section{Demand model description}

The proposed demand model in this study is for the 14 WAPP countries and has been developed with the aim to estimate the current and future hourly electricity demand profiles in these countries. The model has a temporal resolution of 1 hour and the base year is 2016 , while the forecast year is 2030 because all the proposed interconnections in the WAPP are expected to installed and in operation by 2030 [3]. The electricity demand in each country is divided into two components as shown in the flow chart in Figure 1. The first part is the residential demand which is modelled using a bottom-up methodology, to simulate the hourly electricity demand in urban and rural households. The model takes into account the electricity access rates, appliance ownership rates and usage, weather conditions (temperature and humidity), time and type of day, unserved demand, and economic activities The second part is the non-residential demand which is the aggregated industrial, commercial and services demand. The annual nonresidential electricity demand is first forecasted using a top-down methodology, then the hourly demand is modelled based on the forecasted annual demand, cooling coefficients, typical nonresidential demand profiles, and time and type of day. The demand model is written and implemented in MATLAB [40].

\subsection{Residential demand model}

The total hourly electricity demand in the residential sector comprises of demand in both electrified urban and rural households as shown in Eq. (1)

$P_{h}^{d}=P_{h, u}^{d}+P_{h, r}^{d} \quad($ watts $)$

Where $P_{h}^{d}$ is the total electricity consumption in electrified households in an hour of a type of day (weekday or weekend/holiday); $P_{h, u}^{d}$ and $P_{h, r}^{d}$ are the total electricity consumption in urban and rural electrified households respectively in an hour of a type of day. The 2016 electricity access rates for urban and rural households used in the model are from the World Bank's database [1] and presented in Table A.1. The hourly electricity consumption in a type of household can be estimated from several factors such as: electricity consumption of the different appliances, geometry and thermal properties of the household, behavior of household occupants, previously measured load curves and weather conditions [41,42]. However due to the lack of data on the type of construction materials and historical daily electricity consumption of the different types of households in West African countries, only certain factors have been taken into consideration in the developed demand model. They include; occupancy patterns, types and number of appliances, power rating of appliance, probability of use of appliances, daylight hours and weather conditions such as temperature, humidity. The limitation of not including the building envelope properties in the model is that the cooling demand may be overestimated as heat gains in the building materials are not considered. Based on the factors that determine the electricity consumption of appliances in occupied households, the bottom-up demand model is split into 3 components; occupancy dependent appliances, weather and occupancy dependent appliances and lighting. The appliances considered in this demand model and the factors that determine their electricity consumption when households are occupied are presented in Table 1. 

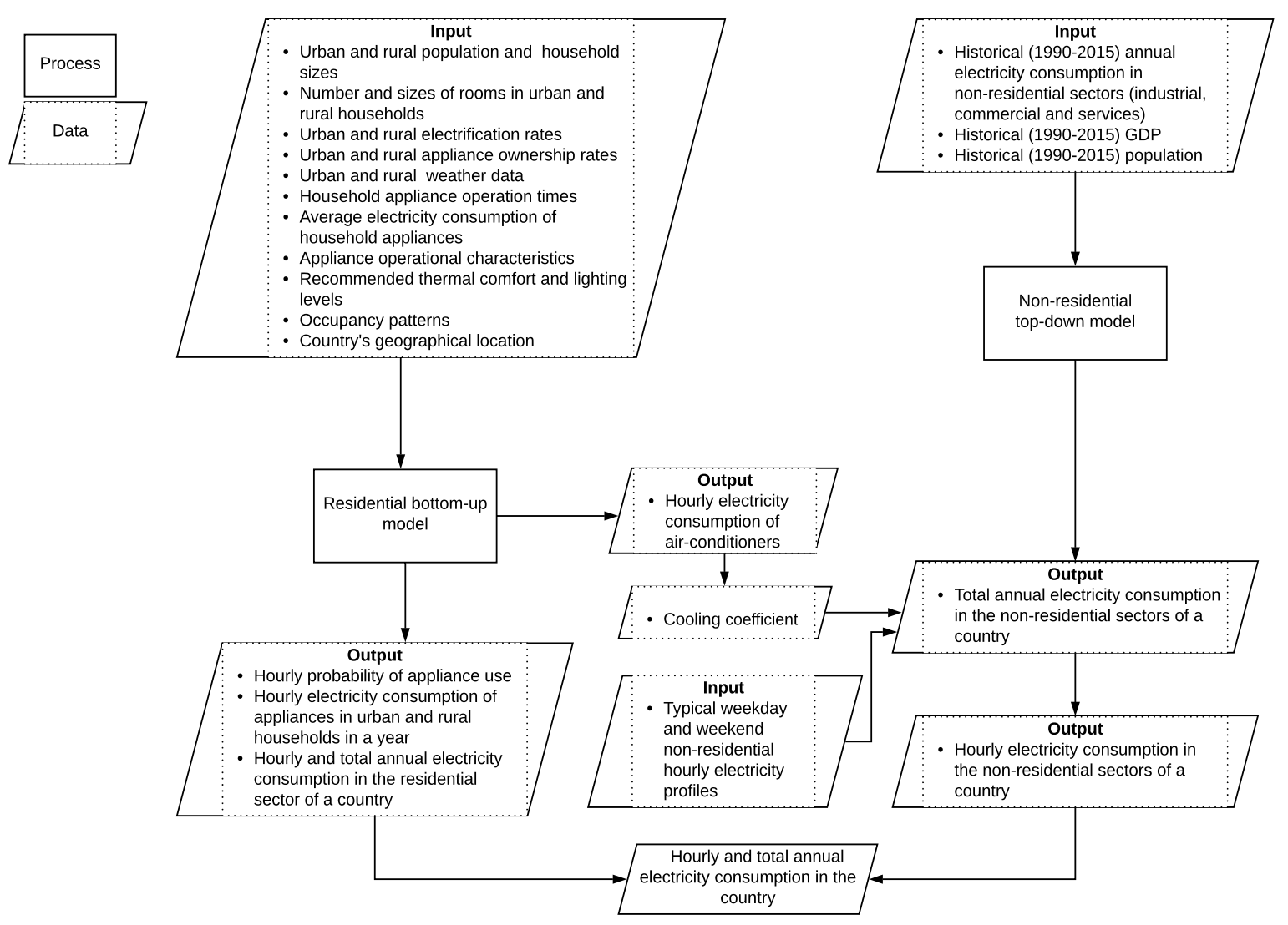

Figure 1. Flow chart of the electricity demand model

The occupancy patterns for the different types of households in this study are based on the type of day and the type of employment of households and hours spent in the different types of employments. The days in the year in the model have been classified into two types: weekdays and weekends/national holidays. For this study, the type of employment of households has been divided into four categories: wage employment, non-farm enterprise, agriculture and stay at home/retired households. Data sources for each country on the different types of employment and their respective share in urban and rural areas are presented in Table A.2. Based on the 2016 national household survey in Nigeria [43], Figure 2 and 3 shows the generated occupancy patterns of urban and rural households in the Nigeria respectively. The share of employment categories in urban and rural households for West African countries is presented in Table A.3.

\begin{tabular}{|lll|}
\hline $\begin{array}{l}\text { Number } \\
1\end{array}$ & $\begin{array}{l}\text { Household appliances } \\
\text { Audio-visual appliances (Televisions, radio and } \\
\text { sound systems) }\end{array}$ & $\begin{array}{l}\text { Electricity consumption factors } \\
\text { Occupancy patterns }\end{array}$ \\
2 & $\begin{array}{l}\text { Cooking appliances (Electric cookers, ovens, kettles, } \\
\text { and microwaves) } \\
\text { Computing appliances (Computers, laptops, and } \\
\text { printers) }\end{array}$ & \\
4 & Washing machines and cloth dryers & \\
\hline 5 & Electric irons & Occupancy patterns and weather conditions \\
\hline 6 & Air conditioners & (Temperature and humidity) \\
\hline 7 & Electric fans & Occupancy patterns and daylight hours \\
\hline 8 & Lighting & \\
\hline
\end{tabular}


Table 1. Household appliances and their respective electricity consumption factors.

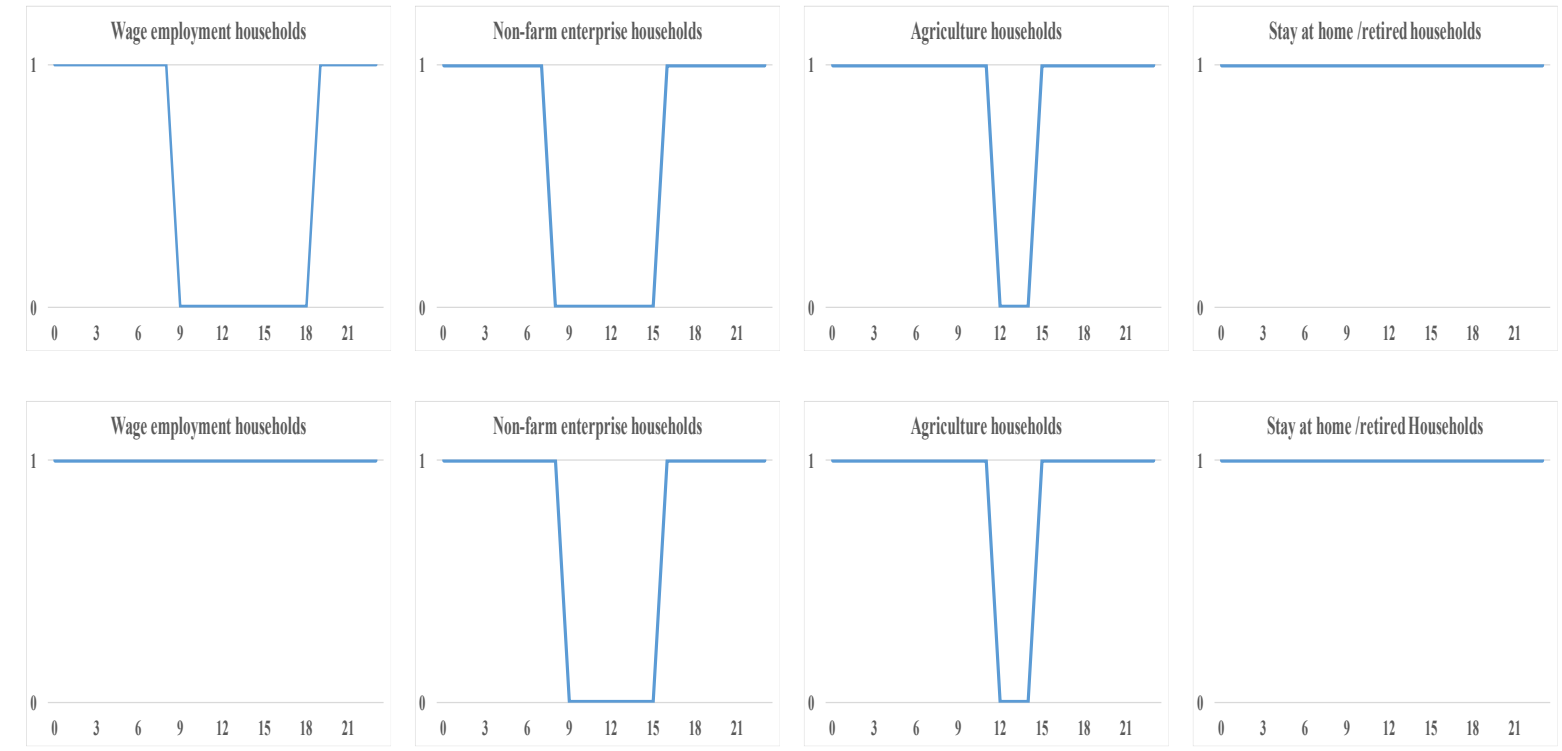

Figure 2. Urban household weekday (Top) and weekend (Bottom) generated occupancy patterns in Nigeria.

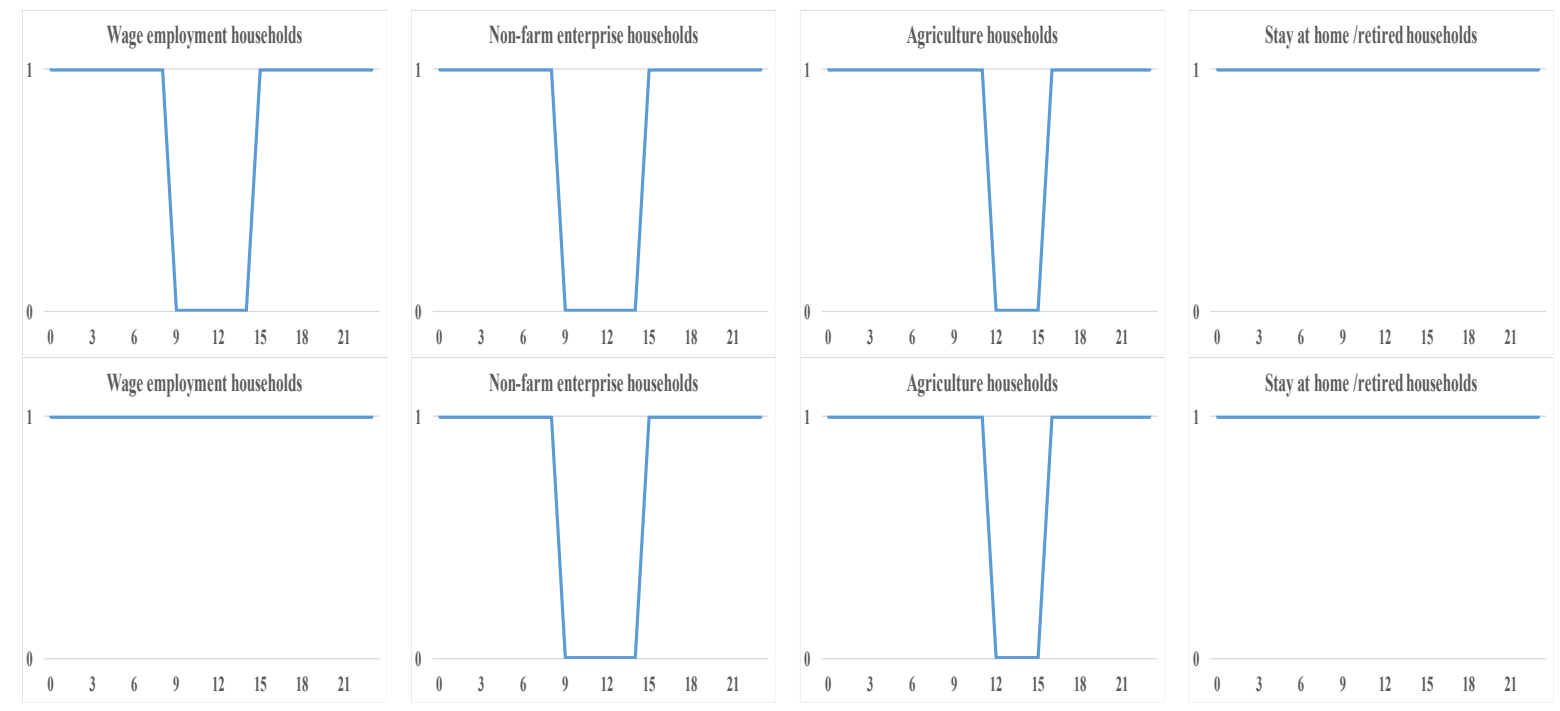

Figure 3. Rural household weekday (Top) and weekend (Bottom) occupancy patterns in Nigeria.

Periods when the households are occupied has a value of 1 and periods when the household is unoccupied has a value of 0 . During periods when the house is not occupied, it is assumed that appliances are not in use, with the exception of cold appliances like fridges and freezers. The electricity consumption of cold appliances fluctuates when the doors are open and also during defrosting, however given that this demand model has a temporal resolution of 1 hour, we assume all cold appliances have a constant electricity usage pattern throughout the day. Figure 4 presents the flow chart of the bottom-up demand model used to generate the hourly demand profile for the residential sector in each country. Due to insufficient electricity generation 
capacity in all the countries, daily load shedding is carried out by the system operators and electricity outages are experienced in the residential sector. The model takes into account these outages [1] for both urban and rural households.

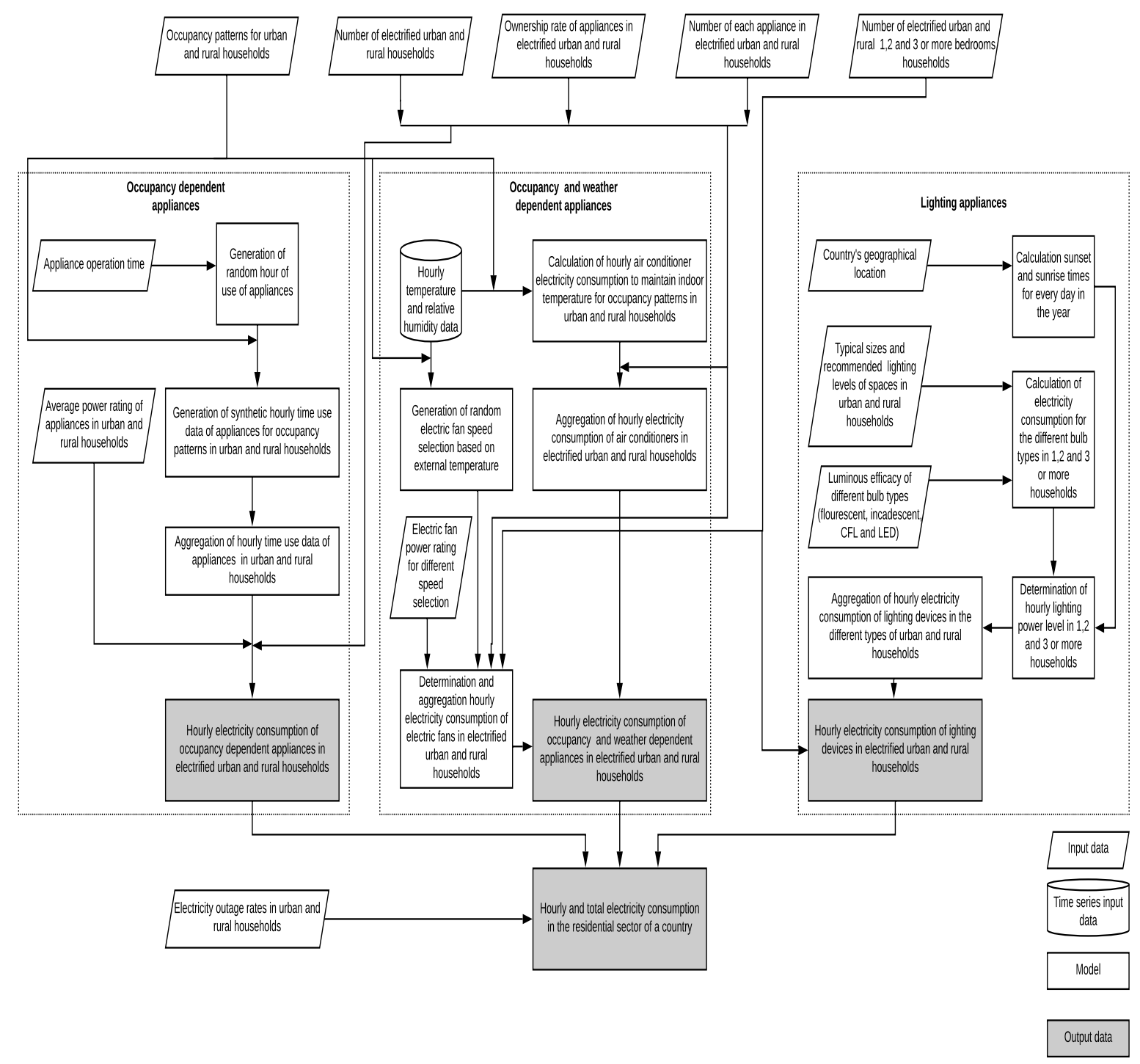

Figure 4. Flow chart of the bottom-up residential sector demand model.

\subsubsection{Occupancy dependent appliances}

The occupancy dependent appliances are appliances whose use is strongly dependent on household member's behaviours when present in the house. These appliances which are presented in Table 1 are; audio-visual, cooking, computing, cloth dryer, electric iron and washing machines. When occupants are not present in the households, appliance are assumed to have a power rating of $0 \mathrm{~W}$ and when in use during occupancy hours, these appliances are assumed to have a constant power rating value as shown in Table A.4. Given that appliances have ranges of power ratings which vary between manufacturers, urban households are assumed to have the lower range and rural households are assumed to have the higher ratings. 
The use of appliances in homes is very random as it is dependent on the unpredictable behaviours of occupants in the household. The TU survey data for households is best obtained through measurement data from households as used in previous studies $[16,20,25,44,45]$. However, due to the lack of TU survey data in West African countries, synthetic TU data is generated. Therefore, to determine the probability of use of appliances during occupancy periods, a stochastic time use model is developed for the different occupancy patterns in urban and rural households. A random number generator, occupancy patterns from national surveys and appliance operation times [46] are used to generate synthetic hourly probability of appliance use for each of the electrified household. For washing machines and cloth dryers, the operating time runs consecutively, so the random generator generates sequential hourly probability use patterns for these appliances. Occupancy hours are split into active and inactive hours, during inactive hours it is assumed that household occupants are asleep or resting and have a relatively lower probability of using appliances. The probability of use of each appliance in households as shown in Eq. (2) is aggregated according to the type of household (urban and rural). The aggregated hourly electricity consumption for each appliance in a type of household is calculated using Eq. (3) and illustrated in Figure 4.

$\sum_{i=1}^{24} U_{a, t, h}^{d}=1$

$P_{a, t, h}^{d}=N_{a, t} * U_{a, t, h}^{d} * R_{a, t} *\left(O_{a, t} * H_{t}\right)$

Where $U_{a, h}^{d}$ is the probability of use of an appliance (a), in a type of household (t), in an hour (h) of a type of day (d). $P_{a, t, h}^{d}$ is the electricity consumption of an appliance in a type of household in an hour of a type of day. $N_{a, t}$ is the number of an appliances in a type of household and is assumed to be one for each household, with the exception of computing devices which are assumed to be 1 in one and two bedroom households and 2 in 3 bedrooms and above households. $R_{a, t}$ is the electricity power rating of an appliance in a type of household as presented in Table A.4. $O_{a, t}$ is the ownership rate of an appliance in a type of household. $H_{t}$ is the population of electrified type of household. Table A.2 contains details on the data sources for household sizes, number of bedrooms in each type of household and appliance ownership in each country. Figure 5 and 6 show the synthetic probability of use of cooking and audio-visual appliances in urban and rural households during weekdays and weekends/holidays in Nigeria. The probability of use of other occupancy dependent appliances in Nigeria can be seen in the Figures A.1 and A.2.
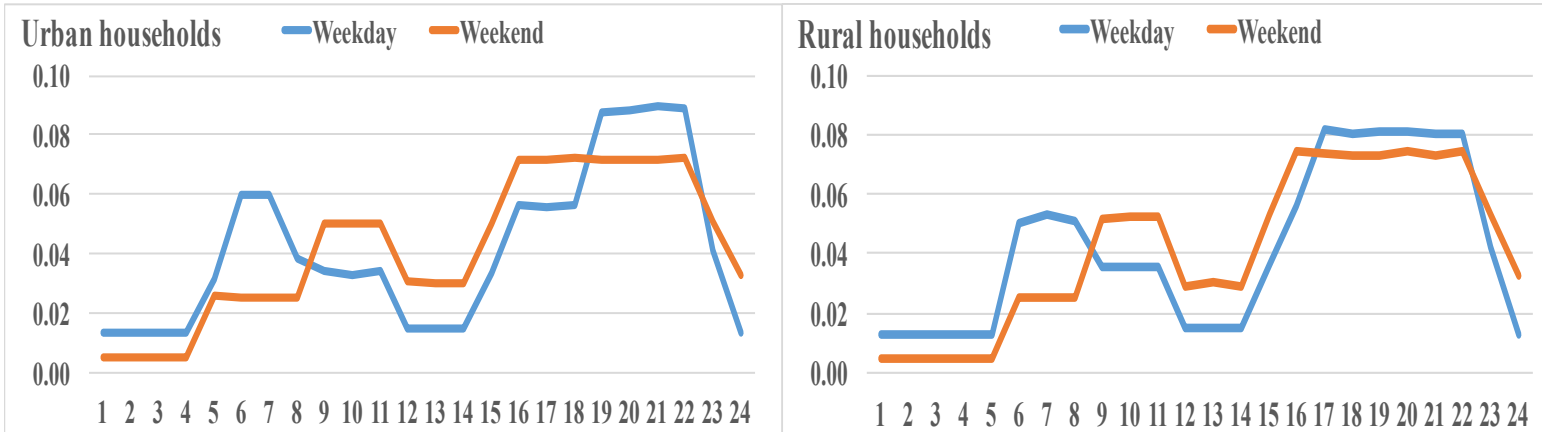

Figure 5. Probability of use of cooking appliances in urban and rural households in Nigeria. 


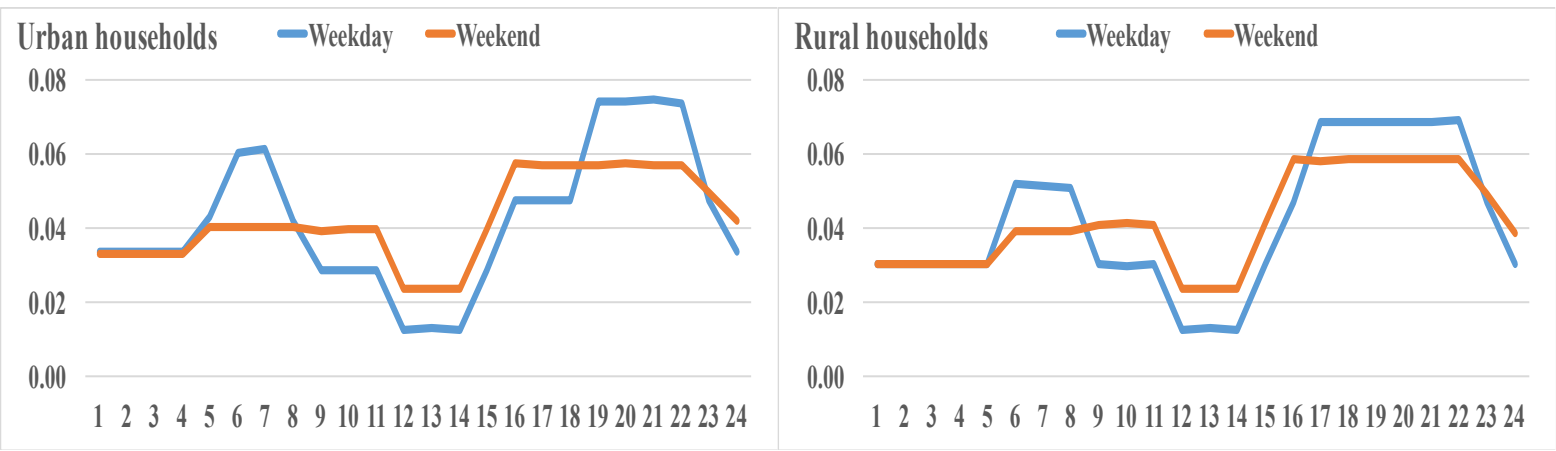

Figure 6. Probability of use of audio-visual appliances in urban and rural households in Nigeria.

\subsubsection{Weather and Occupancy dependent appliances}

The weather and occupancy dependent appliances as presented in Table 1 are air conditioners and electric fans. The use of air conditioners and electric fans in households is dependent on household members' presence and on both external and internal temperature and relative humidity levels. Air conditioners are automatic devises that provide thermal comfort by maintaining a pre-set internal temperature level, through the process of using electricity to move heat from indoor to outdoor. The electricity consumption of an air conditioner in an hour to maintain a set temperature when the household is occupied is calculated using Eq. (4)

$P_{\text {cooling }, h}=q * \rho * \Delta h, h$

Where $q$ is the air conditioner's air flow rate $\left[0.1 \mathrm{~m}^{3} / \mathrm{s}\right], \rho$ is the density of air $\left[1.202 \mathrm{~kg} / \mathrm{m}^{3}\right]$ and $\Delta h_{, h}$ is enthalpy difference [kj/kg] between indoor and outdoor air at hour (h), and is calculated from Eq.(5).

$\Delta h_{h}=h_{o, h}+h_{i, h}$

Where $h_{o, h}$ and $h_{i, h}$ are the enthalpy of outdoor air and indoor air in an hour respectively, which are both calculated using Eqs.(6) -(10). When the enthalpy of the outside air is less than that of the inside air, the air conditioner unit is assumed to go into standby mode and power consumption is assumed to be $0.9 \mathrm{~W}$

$$
\begin{aligned}
& h_{T}=h_{a T, h}+\left(H R_{T, h} * h_{g T, h}\right) \\
& h_{a T, h}=C_{p a} * T_{h} \\
& H R_{T h}=0.622 *\left(\frac{p_{w T, h}}{p-p_{w T, h}}\right) \\
& p_{w T, h}=p_{s, T} * H_{h} \\
& h_{g T, h}=h_{w}+\left(C_{p w} * T_{h}\right)
\end{aligned}
$$

At a temperature (T) in the hour (h), $h_{a T, h}$ is the specific enthalpy of dry air, $H R_{T, h}$ is humidity ratio, and $h_{g T, h}$ is specific enthalpy of water vapour. Calculating the specific enthalpy of dry 
air is dependent on $C_{p a}$, the specific heat of air, $\left[1.006 \mathrm{~kJ} / \mathrm{kg}^{\circ} \mathrm{C}\right]$ and $T_{h}$ is the temperature $\left[{ }^{\circ} \mathrm{C}\right]$ in that hour. The 2016 external hourly temperature and relative humidity data for the urban and rural cities with the highest electricity access rates for each country is gotten from [47], while the target internal hourly temperature is set at $22^{\circ} \mathrm{C}$ to provide thermal comfort [48]. The humidity ratio at a certain temperature in an hour is based on $p_{w T, h}$, the water vapour pressure and $p$, the atmospheric pressure [101325 Pa]. The water vapour pressure is calculated from $p_{s, T}$, saturation vapour pressure and hourly relative humidity. The indoor relative humidity is set at $45 \%$.The specific enthalpy of water vapour is calculated from $T_{h}$; the hourly temperature, $h_{w}$; the specific enthalpy of water vapour at $0^{\circ}[2501 \mathrm{~kJ} / \mathrm{kg}]$, and $C_{p w}$; the specific heat of water vapour $\left[1.86 \mathrm{~kJ} / \mathrm{kg}^{\circ} \mathrm{C}\right]$.

Maintenance of indoor temperature is also dependent on heat loss through the wall and windows of the buildings, however due to insufficient data about the building materials of the different buildings in the West Africa region, these heat losses are not taken into consideration in this demand model. This may result in an overestimation of the electricity consumption of air conditioners, as less electricity consumption will be needed to maintain the internal temperature.

Unlike the air conditioner, majority of the electric fans are not automatic and are operated manually. The electricity consumption of electric fans is therefore assumed to be dependent on the speed of the fan, which is set manually by the user. For the demand model, the electrical fan is assumed to have a maximum power rating of 70 watts, and a 5 speed selection regulator fan with $60 \%$ minimum regulation. The electricity consumption of the electric fan in an hour when the household is occupied is determined using Eq. (11).

$$
P_{\text {fanh }}=\left\{\begin{array}{l}
P_{\text {max }, t} \\
P_{o f f, t} \\
P_{k, t} \\
22{ }^{\circ} \mathrm{C}<T_{e}<27^{\circ} \mathrm{C} \\
T_{e} \leq 22^{\circ} \mathrm{C}
\end{array}\right\}
$$

Where $P_{\max , t}$ is the maximum electricity consumption [70W], $P_{o f f, t}$ is the electricity consumption of the when switched off [0W], and $P_{k, t}$ is electricity consumption in one of the other 4 speed selections shown in Table A.5. The total hourly electricity consumption of air conditioners and fans is calculated using Eq. (12) and illustrated in Figure 4.

$P_{a, t, h}^{d}=N_{a, t} * O_{a, t} * H_{t}$

For the number of appliances $N_{a, t}$, each type of household is assumed to have only one air conditioner unit. 1,2, and 3 bedrooms urban and rural households are assumed to have 1,2, and 3 units of electric fans respectively. $O_{a, t}$ is the ownership rate of an appliance in a type of household. $H_{t}$ is the population of electrified type of household.

\subsubsection{Lighting appliances}

The electricity consumption of lighting appliances in a household depends on occupancy in the household, daylight illumination level, type of lighting bulbs, type of household and number and type of spaces in the household. The required artificial light (lumens) for each type of space in urban household is calculated using Eq. (13). The total artificial light required in rural 
households are assumed to be $40 \%$ the values in urban households due to assumed ignorance of recommended standards and also relatively higher poverty rates.

$L s_{s, u}=\frac{A_{s} * I_{S}}{C U * L f}$

Where $A_{s}$ is the area of the space $\left(\mathrm{m}^{2}\right), I_{S}$ is the recommended lightning level (Lux) [49] for the space, $C U$ is the coefficient of utilization assumed to be 0.6 , and $L f$ is the light loss factor assumed to be 0.8 . The sizes, numbers and recommended lighting levels assumes for the different spaces in the different sizes of households are presented in Table A.6. The total artificial light required in a household is an aggregate of all the required artificial light in each of the spaces. During daylight hours, daylight illumination is assumed to be 50lux in each space of the household and therefore the required level of illumination for lighting appliances is reduced, and the required artificial light is calculated using Eq. (14).

$L d_{s, u}=\frac{A_{s} *\left(I_{s}-50\right)}{C U * L f}$

Daylight period in a day is determined by the sunset and sunrise times in a day, and varies from one country to the other. Eqs. (A.1) - (A.5). are used to determine the sunset and sunrise time for each day of 2016 in each country. The electricity consumption of a type of lighting appliance in an urban household during sunset and daylight hours is calculated using the Eq. (15).

$P s_{b, u}=\frac{\sum L s_{s, u}}{L e} \quad, P d_{b, u}=\frac{\sum L d_{s, u}}{L e}$

Where $L e$ is the luminous efficacy (lumens/watts) of the different bulb types of lighting appliances. The bulb types considered in this study are fluorescent lamps, compact fluorescent lamps (CFL), LED lamps and incandescent lamps. The assumed ownership rate of each type of lamp in each country is presented in Table A.7. Five lighting power levels are assumed for each of the types households, $P_{\text {off }}$ is $0 \mathrm{~W}$ and is when there are no occupants in the household, $P_{\text {activesunset }}$ and $P_{\text {activedaylight }}$ are when the occupants are awake during sunset hours and daylight hours respectively, and in these states we assume $80 \%$ of the all the lighting appliances

in the household are in use. $P_{\text {inactivesunset }}$ and $P_{\text {inactivedaylight }}$ are when occupants are asleep during sunset hours and daylight hours respectively and in these states we assume $10 \%$ of the lighting appliances in the household are in use. The calculation of the total hourly electricity consumption of the different types of lighting is illustrated in Figure 4.

\subsection{Non-residential demand model}

The non-residential component of the demand model consists of the electricity demand in the industrial, commercial and services demand sector of each country. The annual electricity consumption in the non-residential sector of a country in the base year 2016, is modelled using multiple linear regression analysis. Unlike the residential demand sector, a bottom-up approach 
is not used due to the lack of survey data about the buildings and its occupants in these sector. The hourly electricity consumption in the non-residential sector is then synthesized based on the modelled annual demand, cooling coefficients and typical non-residential demand profiles.

\subsubsection{Annual electricity demand}

A multiple linear regression model Eq.(16) is developed using 26 years (1990-2015) of historical annual non-residential demand [50,51], GDP [1] and population data [52],to forecast the 2016 annual electricity demand in the non-residential sectors.

$E_{N R, y}=\beta_{0, a}+\beta_{1} X_{1, y}+\beta_{2} X_{2, y}$

Where $E_{N R, y}$ is the electricity demand in the aggregated non-residential sectors in year $(\mathrm{y})$ in $\mathrm{GWh}, \beta_{0, a}$ is the regression constants for the multiple linear regression model. $X_{1, y}$ and $X_{2, y}$ are GDP in constant US $\$$ and population in year $(\mathrm{y}) . \beta_{1}$ and $\beta_{2}$ are regression coefficient of GDP and population respectively. Table 2 shows the resultant multiple linear regression equations for each country. In order to validate the resultant regression models for all the countries, two statistical test were carried out and their values are presented in Table 2 . The first test is the adjusted coefficient of determination $\left(\mathrm{R}^{2}\right)$, which is used to measure how well the examined data fits the multiple linear model. The value of $\mathrm{R}^{2}$ typically is between 0 and 1 . Burkina Faso and Sierra Leone have the highest and lowest $\mathrm{R}^{2}$ values, with 0.987 and 0.283 respectively. This indicates that both the GDP and population data in the models account for $98.7 \%$ and $28.3 \%$ of the variability in their respective modelled annual electricity demand value. Sierra Leone has a significantly lower $\mathrm{R}^{2}$ value than the other countries and this is due to other factors significantly influencing the annual demand in the non-residential sector, such as the civil war from 1991-2002. The second test is the F-test, which is used to check the overall significant linear regression relationship between the dependent variable (annual electricity demand) and the independent variables (GDP and population). The critical F-value of the models with $(2,23)$ degrees of freedom at $5 \%$ level of significance is 3.42 . The F-statistical values of each of the models (Table 2) is greater than the critical $\mathrm{F}$ value, therefore all the multiple linear regression models for each country is significant.

Furthermore, a validation test is carried out on the multiple regression model for each country by excluding data between 2013 and 2015 from the dataset, and testing the results from the model against actual data in these years. The results from these tests are presented in Table A.8. The results show that for each of the three years tested, most of the countries have high forecasting performance. With 8 countries having relative errors less than $10 \%$ and 5 countries having less than $15 \%$ relative error. However, Sierra Leone had a significant relative error of up to $79 \%$, which could be attributed to the previously mentioned 11-year civil war in the country. These aforementioned tests indicate that the presented multiple regression models for the non-residential sectors, are significant and valid in forecasting the 2016 and 2030 electricity demand.

\begin{tabular}{|llll|}
\hline Country & Multiple linear regression model & Adjusted R & F-statistic value \\
\hline Benin & $E_{N R, y}=-418.3+1.87 e^{-8} X_{1, y}-8.42 e^{-5} X_{2, y}$ & & \\
Burkina Faso & $E_{N R, y}=228.7+1.34 e^{-7} X_{1, y}-6.28 e^{-5} X_{2, y}$ & 0.969 & 393 \\
Cote D'Ivoire & $E_{N R, y}=-1685+7.91 e^{-8} X_{1, y}+7.88 e^{-5} X_{2, y}$ & 0.987 & 924 \\
Gambia & $E_{N R, y}=-71.1+1.13 e^{-7} X_{1, y}+5.01 e^{-5} X_{2, y}$ & 0.936 & 272 \\
Ghana & $E_{N R, y}=3866.3+1.72 e^{-7} X_{1, y}-2.04 e^{4} X_{2, y}$ & 0.883 & 95 \\
Guinea & $E_{N R, y}=-75.2-5.95 e^{-9} X_{1, y}+4.32 e^{-5} X_{2, y}$ & 0.762 & 41 \\
\hline
\end{tabular}




\begin{tabular}{|llll|}
\hline Guinea Bissua & $E_{N R, y}=25.9+3.56 e^{-8} X_{1, y}-2.59 e^{-5} X_{2, y}$ & 0.460 & 11.6 \\
Liberia & $E_{N R, y}=-75.9-2.75 e^{-8} X_{1, y}+6.06 e^{-5} X_{2, y}$ & 0.953 & 257 \\
Mali & $E_{N R, y}=-1123.5-8.24 e^{-8} X_{1, y}+1.7 e^{-4} X_{2, y}$ & 0.897 & 110 \\
Niger & $E_{N R, y}=-66.4+8.33 e^{-8} X_{1, y}-8.08 e^{-6} X_{2, y}$ & 0.962 & 315 \\
Nigeria & $E_{N R, y}=3033.3+2.49 e^{-8} X_{1, y}-1.96 e^{-5} X_{2, y}$ & 0.946 & 219 \\
Senegal & $E_{N R, y}=-786.1+1.22 e^{-7} X_{1, y}+5.36 e^{-5} X_{2, y}$ & 0.944 & 212 \\
Sierra Leone & $E_{N R, y}=136.2+4.66 e^{-8} X_{1, y}-3.16 e^{-5} X_{2, y}$ & 0.283 & 5.93 \\
Togo & $E_{N R, y}=-69.13+1.39 e^{-7} X_{1, y}-2.10 e^{-6} X_{2, y}$ & 0.734 & 35.5 \\
\hline
\end{tabular}

Table 2. Non-residential annual electricity demand models and test results.

\subsubsection{Hourly electricity demand}

In order to estimate the hourly electricity demand in the non-residential sector based on the modelled annual demand, several factors are considered. They include weather, type of day, typical hourly trends in the sector and are expressed in Eqs. (17) - (19).

$$
\begin{aligned}
& P_{N R, h}=\frac{E_{N R, y}}{N} * \frac{H C_{h}+H_{h}}{2} \\
& H C_{h}=\frac{N}{\sum_{h=1}^{N} P_{\text {cooling }, h}} * P_{\text {cooling }, h} \\
& H_{h}=\frac{H_{I, h}+H_{S, h}+H_{C, h}}{3}
\end{aligned}
$$

Where $P_{N R, h}$ is the electricity consumption in non-residential sectors in hour (h), $H C_{h}$ is the hourly cooling coefficient of the non-residential sectors, $H_{h}$ is typical hourly coefficient of non-residential sectors, and $N$ is the total number of hours in the year (8784 in 2016). The cooling coefficient is estimated from the electricity consumption of an air conditioner (Eq.4), and therefore takes into account the temperature and humidity in each day throughout the year. In addition, the cooling coefficient also takes into consideration the type of day (weekday or weekend/holiday) and generated occupancy patterns of wage employment in urban areas. This is to account for the typical operating hours of non-residential buildings. $H_{I, h}, H_{S, h} H_{C, h}$ are the typical hourly coefficient of industrial, service, and commercial sectors that reflect the trends of electricity demand in these sectors.

\subsection{0 demand model}

The hourly and annual electricity demand for each county in 2030 has been modelled using the same methodology as the base year 2016, however with different datasets. The 2030 annual electricity demand in the non-residential sector and electricity access rates in urban and rural households are forecasted using multiple linear regression models similar to Eq. (16). The independent variables for forecasting annual electricity demand in the non-residential sector are GDP and total population. In addition to the 27 years historical (1990-2016) datasets, forecast datasets (2017-2030) are implemented in the regression models. Population forecast are obtained from [52], while GDP forecast is based on the International Monetary Fund [53] growth rate up to 2023 and a constant growth rate is assumed up to 2030.

In order to assess the performance of the new models that include the 2017-2030 population and GDP forecast dataset, we compare the mean absolute percentage error (MAPE) and the 
root mean square error (RMSE) of the models in Table 2 and the new models for each country. The MAPE and RMSE are defined in Eqs. (20) - (21) and the results are presented in Table 3. The MAPE is used to assess the average absolute relative deviation of the predicted electricity demand values from their corresponding measured values. The RMSE indicates the fit of the multiple regression model, by measuring the variance of the error between the measured electricity demand and model's predicted values. Therefore, the smaller the RMSE, the better the fit of the model. From the results in Table 3, the new models for all the countries with the 1990-2030 dataset performed better in terms of forecasting accuracy, as they have lower MAPE values than the models with 1990-2015 dataset. With the exception of Cote $d$ Ivoire and Guinea Bissua, the RMSE values for all the countries decrease in the new models, thus indicating an improved quality on the fit of the model. This better performance can be attributed to the new models having an addition dataset with significantly lower fluctuations in GDP and population values. Therefore, the GDP and population forecast dataset are suitable for forecasting the 2030 non-residential electricity demand.

$R M S E=\sqrt{\frac{1}{n-k} \sum_{y=1}^{n}\left(E_{y}-\dot{E}_{y}\right)^{2}}$

$\operatorname{MAPE}(\%)=\frac{1}{n} \sum_{y=1}^{n} \frac{\left|E_{y}-\hat{E}_{y}\right|}{E_{y}}$

Where $E_{y}$ and $E_{y}$ are the measured and predicted electricity demand in the non-residential sector in year (y) respectively. $n$ is the number of years in the data set and $k$ is the number of regression coefficients in the model.

On the other hand, 2030 electricity access rates in urban and rural households for each country are forecasted based on urban and rural population respectively [52] and GDP. Average household sizes and appliance ownership rates with the exception of lighting devices are forecasted based on the growth trends in the last three national household surveys carried out in each country. More details on national surveys for each country is provided in Table A.2. The type of lighting bulbs used in households in 2030 is based on national lighting efficiency plans. For countries with no national plans, lighting efficiency policies with the aim of reducing usage of incandescent lamps are assumed and presented in Table A.9. We assume all countries have sufficient generation capacities and reserve margin in 2030, therefore system operators do not carry out daily load shedding and have $0 \%$ forced outage rates. The 2016 weather and generated residential TU datasets are used in the 2030 demand model.

\begin{tabular}{|lllll|}
\hline Country & RMSE $(\mathrm{GWh})$ & RMSE $(\mathrm{GWh})$ & MAPE $(\%)$ & MAPE (\%) \\
\hline Benin & {$[1990-2015$ dataset $]$} & {$[1990-2030$ dataset $]$} & {$[1990-2015$ dataset $]$} & {$[1990-2030$ dataset $]$} \\
Burkina Faso & 22 & 24 & 12 & 7 \\
Cote D'Ivoire & 119 & 17 & 8 & 5 \\
Gambia & 10 & 146 & 7 & 6 \\
Ghana & 382 & 8 & 11 & 7 \\
Guinea & 35 & 298 & 8 & 5 \\
Guinea Bissua & 0.5 & 27 & 10 & 6 \\
Liberia & 9 & 0.8 & 13 & 9 \\
Mali & 88 & 7 & 10 & 7 \\
Niger & 18 & 69 & 26 & 14 \\
Nigeria & 580 & 14 & 8 & 5 \\
Senegal & 115 & 452 & 5 & 3 \\
\end{tabular}




\begin{tabular}{|lllll|} 
Sierra Leone & 20 & 16 & 36 & 23 \\
Togo & 49 & 38 & 14 & 9 \\
\hline
\end{tabular}

Table 3. Performance metrics of the multiple regression models.

\section{Results}

\subsection{Validation}

The developed demand model for West African countries is validated by comparing its 2016 annual and monthly results with actual data for each country. Table 4 shows actual $[50,54]$ and simulated 2016 annual electricity demand for each country by sector. The results for the residential sector in the model varies from the actual data, with the demand in most of the countries overestimated as indicated by the relative error in Table 4 . These variations between the results from the residential model and actual data can be attributed to three major assumptions in the model. First, not all household appliances have been simulated individually, with four categories (Table 1) which aggregate similar appliances implemented in the model. Second, for the lighting demand the model assumes that the different rooms in urban and rural households have the same required lumens. Third, the hourly demand simulation for air conditioners and electric fans assumes a target indoor temperature and humidity of $22^{\circ} \mathrm{C}$ and $45 \%$ relative humidity respectively for all households. In reality, these target figures will vary significantly from households to household members. For Sierra Leone, the results for the modelled residential sector deviates significantly from the actual 2016 values, with a relative error of $47.5 \%$. In addition to the aforementioned major assumptions to the residential model, this significant difference is also due the 11 years (1991 -2002) of civil war which impacted the electricity demand and is not quantified in the model.

On the other hand, the results from the model for the non-residential sector is similar to actual data from majority of the countries. The relative error of the models' result to the actual data is less than $15 \%$ for all countries with the exception of Sierra Leone having a relative error of $-38.5 \%$. This significant difference can be attributed to the previously mentioned civil war in the country. Overall the model's 2016 total annual electricity demand for most of the countries varies slightly from the 2016 actual data with less than absolute $15 \%$ relative error, with the exception of Guinea Bissua.

\begin{tabular}{|c|c|c|c|c|c|c|c|c|c|}
\hline & $\begin{array}{l}\text { Resident } \\
\text { demand } \\
\text { (GWh) }\end{array}$ & & & $\begin{array}{l}\text { Non- } \\
\text { residenti } \\
\text { demand } \\
(\mathrm{GWh})\end{array}$ & & & $\begin{array}{l}\text { Total } \\
\text { annual } \\
\text { demand } \\
(\mathrm{GWh}) \\
\end{array}$ & & \\
\hline Country & $\begin{array}{l}\text { Actual } \\
\text { demand }\end{array}$ & $\begin{array}{l}\text { Modelled } \\
\text { demand }\end{array}$ & $\begin{array}{l}\text { Relative } \\
\text { error } \\
(\%)\end{array}$ & $\begin{array}{l}\text { Actual } \\
\text { demand }\end{array}$ & $\begin{array}{l}\text { Modelled } \\
\text { demand }\end{array}$ & $\begin{array}{l}\text { Relative } \\
\text { error } \\
(\%)\end{array}$ & $\begin{array}{l}\text { Actual } \\
\text { demand }\end{array}$ & $\begin{array}{l}\text { Modelled } \\
\text { demand }\end{array}$ & $\begin{array}{l}\text { Relative } \\
\text { error } \\
(\%)\end{array}$ \\
\hline $\begin{array}{l}\text { Benin } \\
\text { Burkina }\end{array}$ & 521 & 550 & 5.7 & 781 & 667 & -14.6 & 1302 & 1217 & -6.5 \\
\hline $\begin{array}{l}\text { Faso } \\
\text { Cote d }\end{array}$ & 658 & 583 & -11.3 & 712 & 720 & 1.1 & 1370 & 1303 & -5 \\
\hline Ivoire & 3068 & 3665 & 19.5 & 2832 & 3095 & 9.3 & 5900 & 6760 & 14.6 \\
\hline Gambia & 110 & 88 & -20 & 140 & 153 & 9.3 & 250 & 241 & -3.6 \\
\hline Ghana & 6704 & 5424 & -19 & 6377 & 6370 & -0.1 & 13081 & 11794 & -9.8 \\
\hline $\begin{array}{l}\text { Guinea } \\
\text { Guinea }\end{array}$ & 619 & 668 & 8 & 412 & 403 & -2.3 & 1031 & 1071 & 3.9 \\
\hline Bissua & 20 & 27 & 34 & 15 & 17 & 13.3 & 35 & 44 & 25.1 \\
\hline Liberia & 97 & 92 & -4.8 & 145 & 159 & 9.5 & 242 & 251 & 3.8 \\
\hline Mali & 918 & 974 & 6.1 & 848 & 871 & 2.7 & 1766 & 1845 & 4.5 \\
\hline Niger & 674 & 551 & -18.3 & 450 & 442 & -1.7 & 1124 & 993 & -11.6 \\
\hline Nigeria & 13650 & 14481 & 6.1 & 10294 & 10722 & 5.3 & 23947 & 25203 & 5.2 \\
\hline
\end{tabular}




\begin{tabular}{|llllllllll|} 
Senegal & 992 & 1002 & 1 & 2015 & 2086 & 3.5 & 3007 & 3088 & 2.7 \\
Sierra & & & & & & & & & \\
Leone & 104 & 153 & 47.5 & 96 & 59 & -38.5 & 200 & 212 & 6.2 \\
Togo & 716 & 780 & 8.9 & 586 & 512 & -12.6 & 1302 & 1292 & -0.8 \\
\hline
\end{tabular}

Table 4. Recorded and simulated 2016 annual electricity demand by sector in West African countries.

2016 monthly electricity demand data for nine countries were provided by the WAPP information and coordination center [54]. These are the countries that are currently involved in cross-border electricity trading in the region. The model is further validated by comparing the simulated monthly electricity demand for these 9 countries with the actual monthly demand data which includes transmission and distribution losses. Figure 7 highlights the similar trends between the actual and simulated monthly demand in Benin/Togo, Burkina Faso, Cote d Ivoire, Ghana, Mali, Niger, Nigeria and Senegal, with the countries having a correlation coefficient of 0.8, 0.5, 0.9, 0.8, 0.6, 0.7, 0.6 and 0.8 respectively. The monthly data for Benin and Togo are presented aggregated because the transmission network in both Benin and Togo is operated by a single organization. Burkina Faso, Mali and Nigeria have comparatively lower correlation coefficient (0.5,0.6 and 0.6), and there are noticeable differences between the simulated and actual demand in these countries in certain months. In Burkina Faso and Mali, there were considerable decrease in electricity generation from diesel power plants in July and August due to increased forced outages. While in Nigeria, the decrease in electricity generation from gas power plants in May and June was caused by vandalism to gas pipelines. These sudden disruptions to electricity supply which consequently impacted the electricity demand are not taken into consideration in the model.

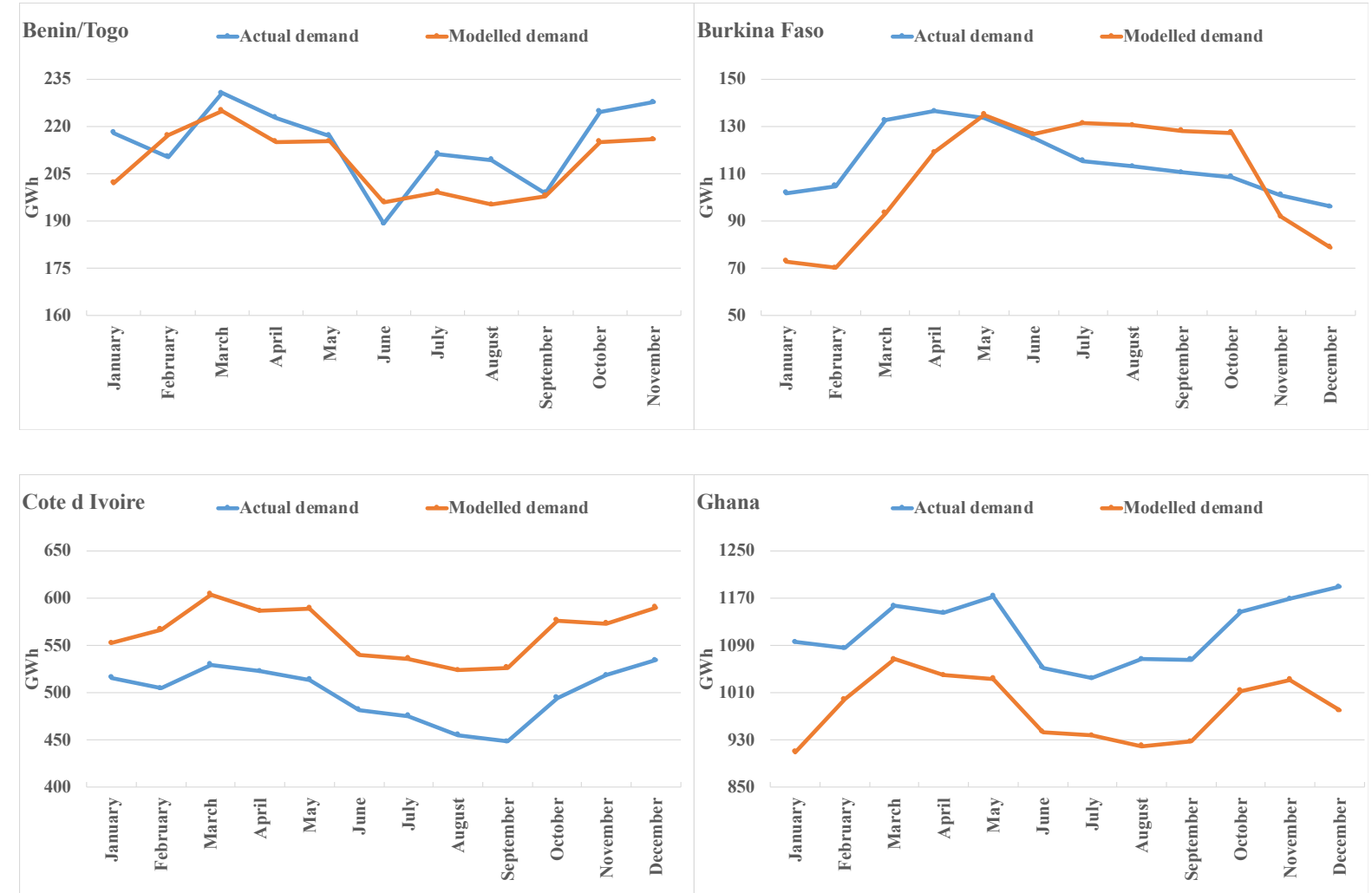




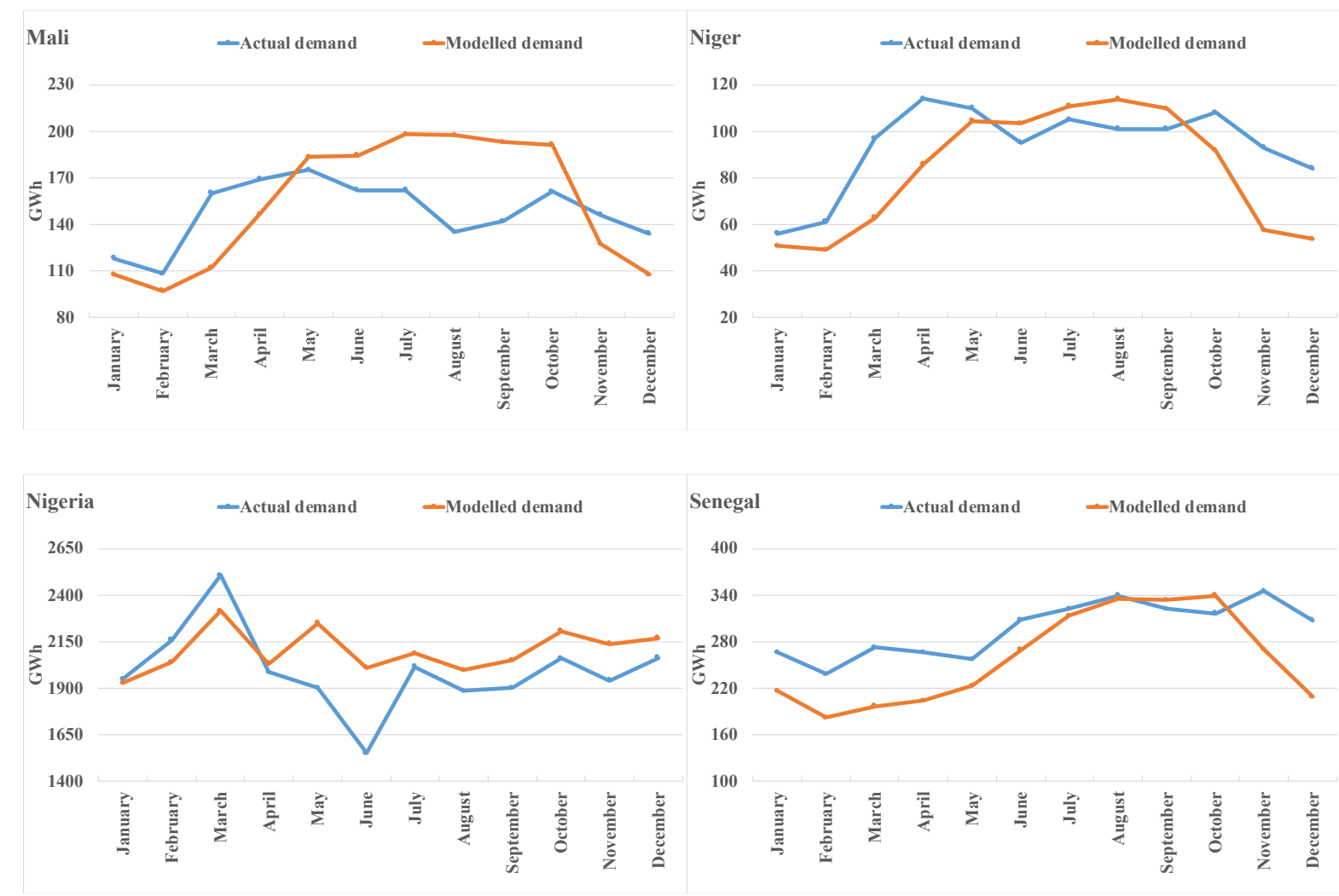

Figure 7. 2016 simulated and actual monthly demand data for 7 countries.

\subsection{Hourly electricity demand profiles}

The hourly electricity demand in urban and rural households on selected days in Guinea Bissua and Nigeria in 2016 are presented in Figure 8 and 9. These are the countries with the lowest and highest demand levels in West African region. The aggregate weekday demand profiles for urban and rural households in both countries have considerably higher peak demand than the weekend/holiday profiles. These demand profiles correspond to the simulated hourly occupancy patterns of household members in the different types of households. In Nigeria, air conditioners and lighting appliances are the predominate source of electricity consumption in urban and rural households respectively. This is due to Nigeria having a comparatively higher ownership rate of air conditioners in urban households $(5.1 \%)$ than in rural households $(1 \%)$. On the other hand, In Guinea Bissua, where the ownership rate of air conditioners in urban households and rural households are $1.7 \%$ and $0 \%$ respectively, majority of the demand in both types of households are from lighting appliances. An estimated 49\% of Nigeria's total population reside in urban areas, however the peak demand on a weekday (April $1^{\text {st }}$ ) in urban and rural households in Nigeria was 2640MW and 287MW respectively. These figures highlight the considerable difference between appliance ownership rates and electricity access rates in urban $(86 \%)$ and rural $(41 \%)$ areas. On the same weekday, Guinea Bissua with an electricity access rate of $30 \%$ and $4 \%$ in urban and rural areas respectively has a peak demand of $5.6 \mathrm{MW}$ and $0.26 \mathrm{MW}$ in its urban and rural households. With an assumed decrease in load shedding, increasing electricity access and appliance ownership rates, the hourly demand profiles during weekdays and weekends changes in all the countries in 2030. Figure A.3 and A. 4 shows the 2030 hourly demand profiles in urban and rural households on selected days in Guinea Bissua and Nigeria. 


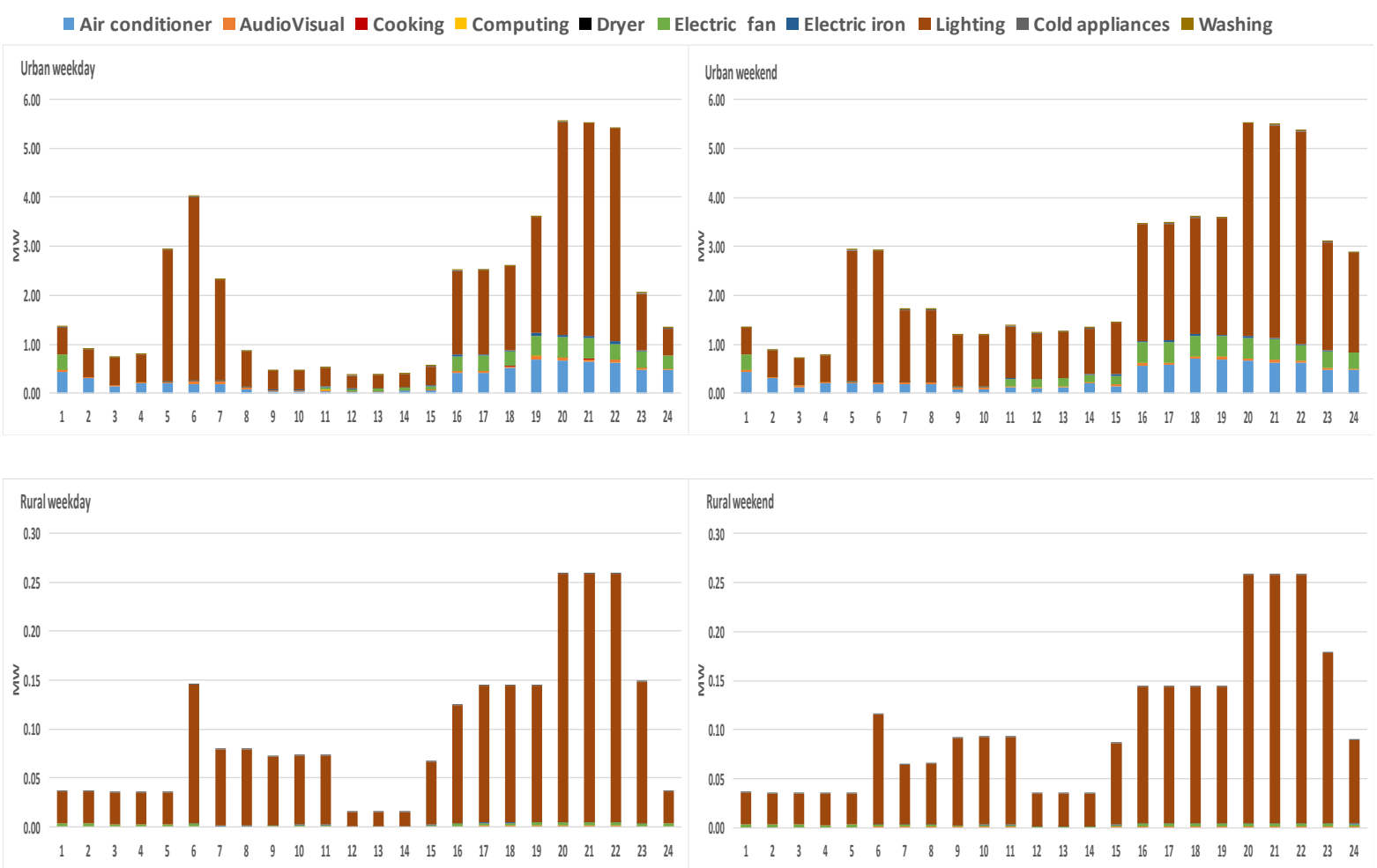

Figure 8. Weekday ( $1^{\text {st }}$ April 2016) and weekend ( $2^{\text {nd }}$ April 2016) simulated residential electricity demand profiles in Guinea Bissau's urban and rural households

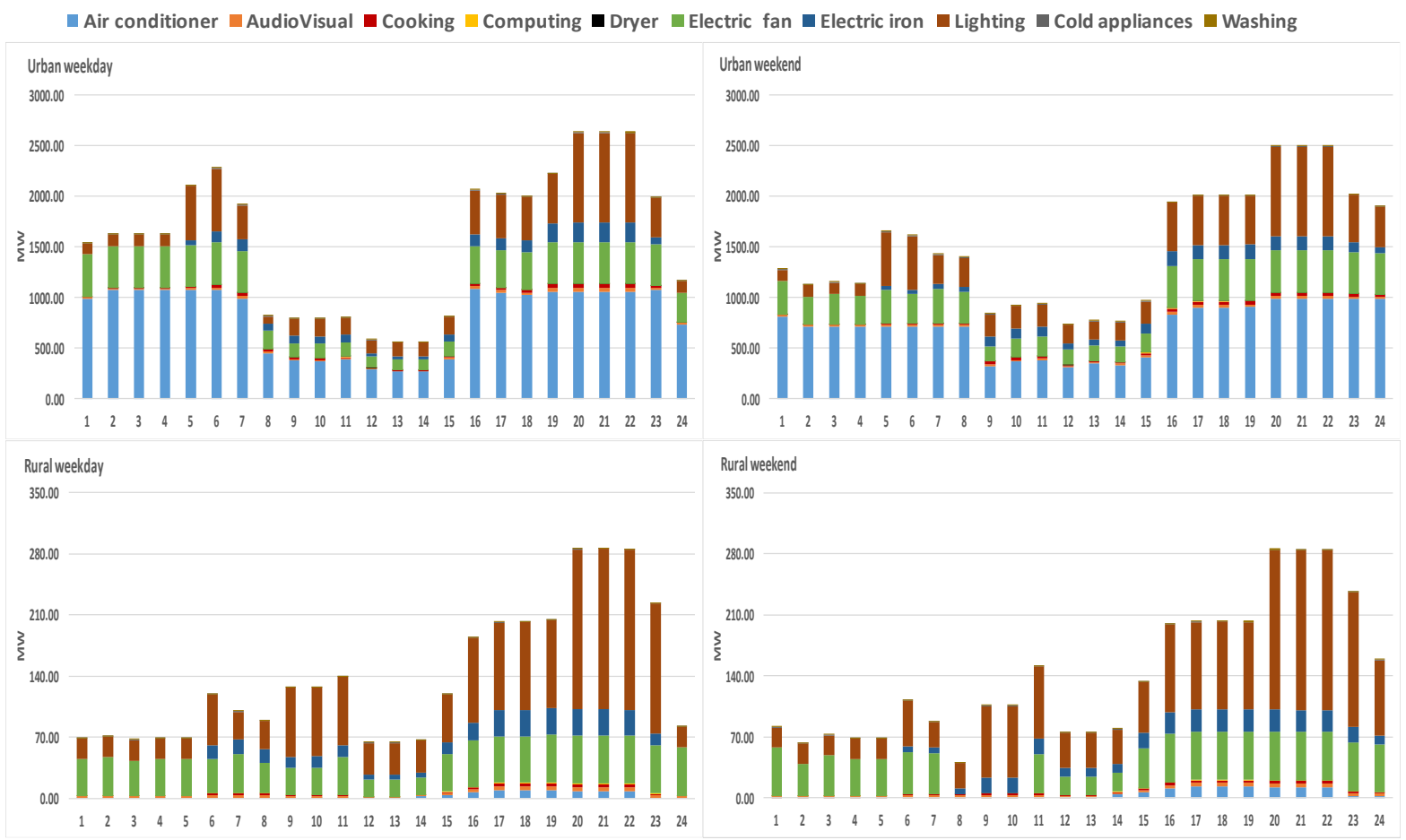

Figure 9. Weekday ( $1^{\text {st }}$ April 2016) and weekend (2 ${ }^{\text {nd }}$ April 2016) simulated residential electricity demand profiles in Nigeria's urban and rural households 


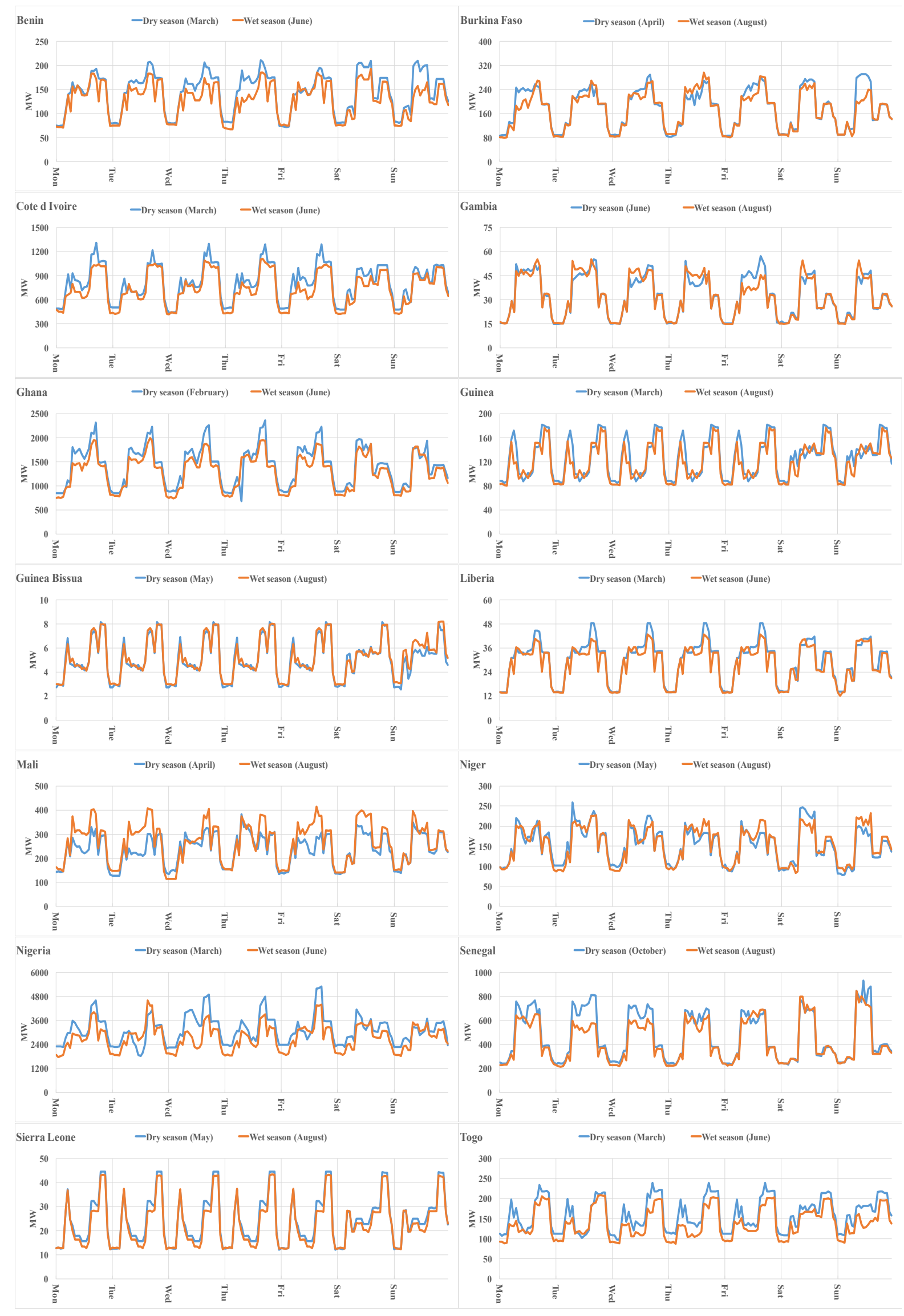

Figure 10. 2016 Hourly demand profiles of representative weeks in dry and wet seasons. 
Electricity demand from cooling appliances (air conditioners and electric fans) plays a significant role in the overall demand in West African countries given their tropical climate. The cooling demand in the residential sector and cooling coefficient in the non-residential sectors are a function of both temperature and humidity. There are two season in West African countries; dry and wet season. These seasons vary from country to country and Figure 10 shows the modelled hourly demand for representative weeks in dry and wet seasons in each of the countries. For most of the countries, the hourly demand in a week in dry season is comparatively higher than the demand in wet season. This is a reflection of the higher temperature and humidity experienced during dry season in these countries and therefore increased use of cooling appliances. In Burkina Faso, Gambia and Guinea Bissua, the hourly demand profiles in the two seasons are quite similar due to little temperature and humidity variations throughout the year in the countries. However, in Mali the hourly demand levels in the wet seasons is observed to be higher than the dry season. This is mainly due to Mali having higher humidity levels in the wet season that in the dry season. The hourly demand profiles for representative weeks in dry and wet seasons for all the countries in 2030 are presented in Figure A.5. The 2030 hourly demand from the model reflects the impact of seasons, increasing electricity access and appliance ownership on future demand in the region, and can be useful for planning short-term unit commitment in each country. Furthermore, with the plans to create a single electricity market in West Africa by 2030, the model provides system operators and capacity planners with a dataset to plan spot electricity market operation in the region.

As shown in Figure 10, the weekdays in both seasons for all the countries have two distinct peak times: early morning and evening. This is as a result of increased occupancy activities in households, and start of the day for the non-residential sectors. Unlike weekdays, the weekend peak times vary from country to country due to increased occupancy of households and thus increased random use of household appliances. Lighting demand is modelled as a function of available daylight hours which varies between the different seasons in some countries. As a result of the different sunset and sunrise times in the two seasons, peak times in countries like Burkina Faso, Cote d Ivoire, Gambia and Senegal, changes between seasons.

\subsection{Annual electricity demand profiles}

The results for the peak and annual electricity demand by sector for West African countries in 2016 and 2030 is presented in Table 5. As expected the lowest and highest peak demand in 2016 and 2030 are in Guinea Bissua and Nigeria respectively, as these are the countries with the highest and lowest population in both years. The peak demand with respect to Guinea Bissua and Nigeria was 20MW and 5360MW in 2016, and 58MW and 30,688MW in 2030. Similarly, the 2030 forecasted peak demand in all the countries increases significantly in comparison to their 2016 levels. The peak times vary from country to country due to the different occupancy patterns, weather conditions and daylight hours experienced in each country. Both the residential and non-residential sectors in all countries experiences an increase in annual demand in 2030 in comparison with 2016, with more increase observed in the latter.

\begin{tabular}{|c|c|c|c|c|c|c|c|c|}
\hline & \multicolumn{4}{|l|}{2016} & \multicolumn{4}{|l|}{2030} \\
\hline Country & $\begin{array}{l}\text { Peak } \\
\text { demand } \\
\text { (MW) }\end{array}$ & $\begin{array}{l}\text { Residential } \\
\text { demand } \\
\text { (GWh) }\end{array}$ & $\begin{array}{l}\text { Non- } \\
\text { residential } \\
\text { demand } \\
(\mathrm{GWh})\end{array}$ & $\begin{array}{l}\text { Total } \\
\text { demand } \\
\text { (GWh) }\end{array}$ & $\begin{array}{l}\text { Peak } \\
\text { demand } \\
\text { (MW) }\end{array}$ & $\begin{array}{l}\text { Residential } \\
\text { demand } \\
\text { (GWh) }\end{array}$ & $\begin{array}{l}\text { Non- } \\
\text { residential } \\
\text { demand } \\
(\mathrm{GWh})\end{array}$ & $\begin{array}{l}\text { Total } \\
\text { demand } \\
\text { (GWh) }\end{array}$ \\
\hline Benin & 240 & 550 & 667 & 1217 & 1292 & 2010 & 3228 & 5238 \\
\hline $\begin{array}{l}\text { Burkina } \\
\text { Faso }\end{array}$ & 317 & 583 & 720 & 1303 & 1989 & 3344 & 3802 & 7146 \\
\hline
\end{tabular}




\begin{tabular}{|c|c|c|c|c|c|c|c|c|}
\hline $\begin{array}{l}\text { Cote d } \\
\text { Ivoire }\end{array}$ & 1355 & 3665 & 3095 & 6760 & 3968 & 9572 & 10403 & 19975 \\
\hline Gambia & 70 & 88 & 153 & 241 & 535 & 716 & 1047 & 1763 \\
\hline Ghana & 2467 & 5424 & 6370 & 11794 & 8013 & 20494 & 20160 & 40654 \\
\hline Guinea & 210 & 668 & 403 & 1071 & 811 & 3307 & 1258 & 4565 \\
\hline $\begin{array}{l}\text { Guinea } \\
\text { Bissua }\end{array}$ & 20 & 27 & 17 & 44 & 58 & 132 & 123 & 255 \\
\hline Liberia & 51 & 92 & 159 & 251 & 253 & 420 & 770 & 1190 \\
\hline Mali & 462 & 974 & 871 & 1845 & 1648 & 3865 & 2576 & 6441 \\
\hline Niger & 260 & 551 & 442 & 993 & 1576 & 3420 & 1850 & 5270 \\
\hline Nigeria & 5360 & 14481 & 10721 & 25202 & 30688 & 120805 & 51532 & 172337 \\
\hline Senegal & 840 & 1108 & 2086 & 3194 & 4367 & 6558 & 8446 & 15004 \\
\hline $\begin{array}{l}\text { Sierra } \\
\text { Leone }\end{array}$ & 45 & 153 & 59 & 212 & 221 & 628 & 520 & 1148 \\
\hline Togo & 248 & 780 & 512 & 1292 & 1015 & 3151 & 2348 & 5499 \\
\hline
\end{tabular}

Table 5. Simulated 2016 and 2030 peak and annual electricity demand by sector in West African countries

In 2016, the residential sector accounts for $53 \%$ of the annual electricity demand in the region, however by 2030 , this share is projected to increase to $62 \%$. This is primarily as a result of the substantial increase Nigeria's residential demand which accounts for $68 \%$ of the total residential demand in the region. The 2030 forecast of the non-residential sector takes into account unserved demand, population and GDP growth. The annual electricity demand in the non-residential sector increases from 26TWh in 2016 to 108TWh in 2030. On the other hand, in addition to unserved demand, population and GDP growth, the 2030 forecast of the residential sector takes into account increase in electricity access and appliance ownership rates in both urban and rural households.

Results from the model show that in 2016, demand from urban households constitutes $91 \%$ of the total residential annual demand (29TWh), with electricity access rates ranging from $30 \%$ in Guinea Bissua to $92 \%$ in Cote d Ivoire. With a share of $9 \%$ in the residential demand mix, rural households' electricity access ranges from $0.8 \%$ in Burkina Faso to $67 \%$ in Ghana. By 2030 , electricity access rates in urban households ranges from $26 \%$ in Liberia to $100 \%$ in Cote D Ivoire, Guinea, Senegal and Togo. While electricity access rates in rural households ranges from $1.1 \%$ in Burkina Faso to $100 \%$ in Ghana. Furthermore, there is barely any change in the urban/rural demand mix as urban households account for $92 \%$ of the annual residential demand (178TWh) in 2030. Therefore, based on the projected annual GDP and population (urban and rural) growth rate, the results from the model indicate that the ECOWAS ambitious target of $100 \%$ electricity access by 2030 in all member countries will not be achieved. The electricity access rates for all the countries in 2016 and 2030 is presented in Table A.1.

Figure 11 shows the modelled residential electricity demand mix for West African countries in 2016 and 2030. In 2016, with the exception of Cote D Ivoire, Ghana, and Nigeria, lighting demand accounted for more than $50 \%$ of the residential demand in each country. However, all the countries are expected to experiences a decrease in the share of lighting demand by 2030. This is as a result of the assumed national lighting efficiency policies (Table A.9) implemented in the model. These policies vary from country to country with the goal of significantly reducing the use of incandescent lamps and integrating more CFL and LED bulbs in the households. In 2016, the share of cooling appliances (air conditioners and electric fans) in the total residential demand mix vary from $18 \%$ in Liberia to 64\% in Nigeria. By 2030, based on the forecasted increase of electricity access rates in the model, cooling appliances are projected to account for at least $50 \%$ of the total residential demand in each country. 
The 2016 annual demand results from the model are compared with the results in the WAPP master plan [12], and are presented in Table A.10 . The demand values from our model are lower than the results in the 2016 base demand scenarios in the master plan, with our results closer to the actual 2016 values for each country. The lower demand values in our model can be attributed mostly to two factors. First in the WAPP master plan, demand forecast is based on 10 years historical GDP and population growth rates for each country, while demand in the non-residential sectors of our model is based on 26 years historical GDP and population growth rates. Second, our model does not aggregate the residential sector and is able to account for the varying electricity access rates in urban and rural areas. Overall our modelled annual electricity demand in the West African region is estimated to reach five times its actual 2016 levels, from 55TWh to 286TWh.

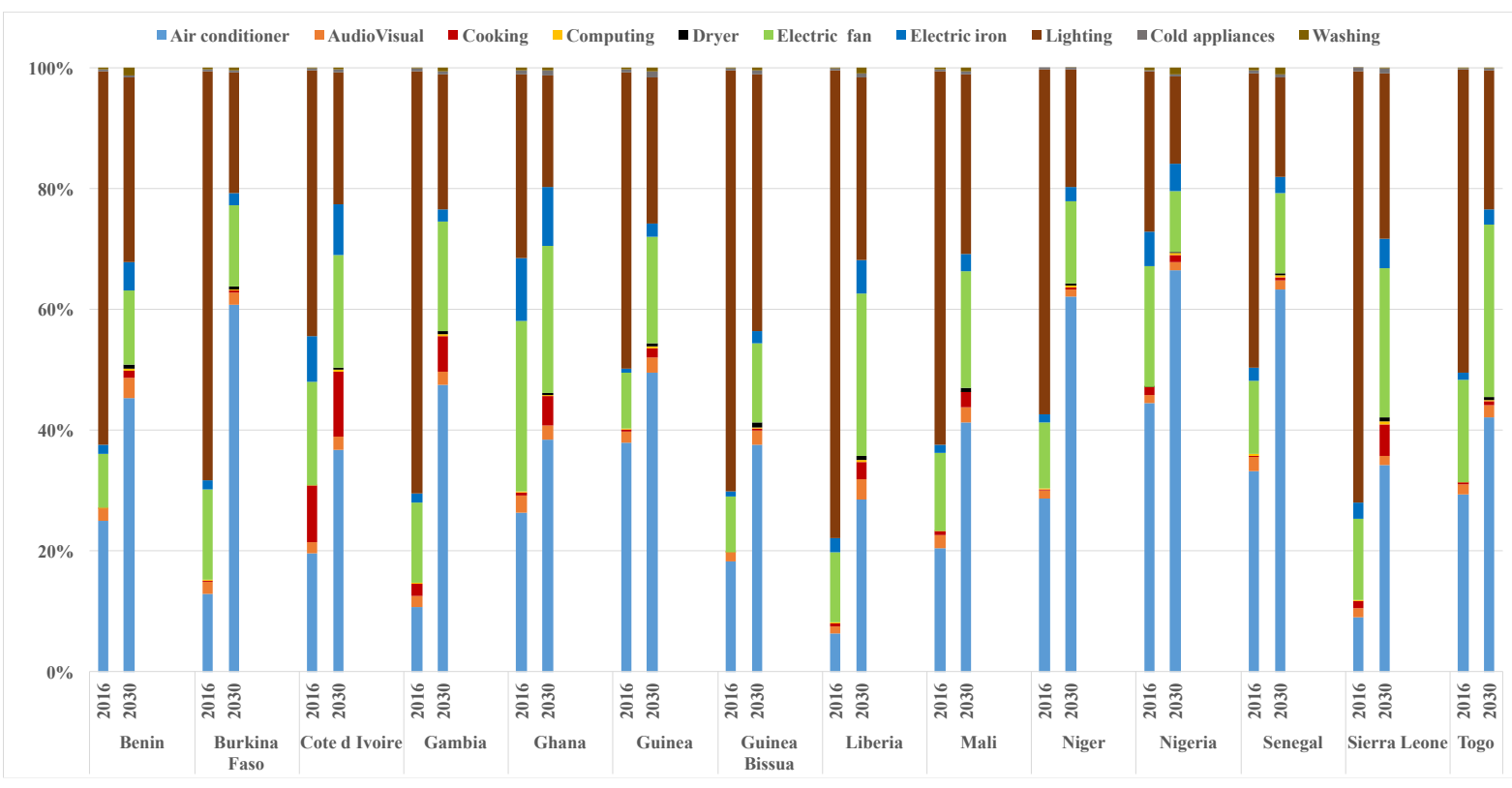

Figure 11. 2016 and 2030 simulated residential electricity demand mix in West African countries

\section{Conclusion}

Low electricity access rates and daily load shedding due to insufficient generation and capacities are key factors that hinder the economic development of developing countries. Modelling and forecasting electricity demand plays an important role in the long and short term planning of electricity supply to provide reliable access to electricity. In developing countries, modelling hourly electricity demand has been a challenge, due to scarcity of historical demand data and methodological frameworks that adequately capture technology transitions and urbanrural energy divide. This study develops a hybrid demand model for 14 West African countries in 2016 and 2030,using bottom-up and top-down methodology to simulate and forecast hourly and annual electricity demand. Hourly electricity demand in electrified urban and rural households are modelled by taking into account nine categories of household appliances, occupancy patterns of household members, weather (temperature and humidity) conditions, type of day and daylight hours. Synthetic hourly probability of use of household appliances are generated using average appliance operation times, occupancy patterns from national surveys and a random generator. 2030 electricity access rates in urban and rural households are forecasted using multiple linear regression methodology. The demand model for the non- 
residential sectors is developed using 26-years historical GDP and population dataset, weather dataset, type of day and typical hourly demand coefficients.

The developed model is validated using actual 2016 annual and monthly electricity demand data of West African countries. The model's annual demand for 13 out of 14 countries had an absolute relative error of $15 \%$ in comparison to the actual data. The actual and modelled monthly electricity demand of the 9 countries assessed had correlation coefficients ranging from 0.5 to 0.9 . The significant deviations in monthly trends can be attributed to the sudden decrease in monthly electricity generation, as a result of the forced outages of power plants which were not taken into consideration in the model. Results from our model indicate that in 2016, more than $50 \%$ of the residential demand in 11 countries come from lighting appliances. However, as electricity access and appliance ownership rates increase in 2030 , at least $50 \%$ of the total residential demand in each country is forecasted to come from cooling appliances (air conditioners and electric fans). Policy makers in each of the West African countries therefore have an opportunity to significantly improve its energy efficiency, by implementing policies targeted at increasing the use of air conditioners with relatively higher energy efficiency ratio.

The relationship between weather conditions and electricity demand is presented in our study by comparing weekly electricity demand during wet and dry season in each country. With most countries having comparatively higher demand in dry seasons than in wet seasons, due to the increased utilization of cooling appliances. Results from the 2030 demand model indicate that annual electricity demand in the West African region is expected to be five times its 2016 levels, with most of the countries experiencing more increase in the non-residential sectors in comparison to the residential sector. Thus highlighting the need for investment in both operating and reserve generation capacities, to ensure the elimination of load shedding in West African countries by 2030. Furthermore, contrary to the target by the Economic Community of West African States to achieve $100 \%$ electricity access by 2030 in all countries, results from the model indicate only four countries achieve $100 \%$ electricity access in its urban areas and one country in its rural areas by 2030 .

The 2030 hourly demand datasets produced in this study can be useful in evaluating regional targets to increase integration of renewable energy sources and cross-border electricity trading in an interconnected West African electricity grid. The study area in this study is West Africa, however the methodology developed in this study can be applicable in modelling hourly and annual electricity demand in other developing countries that have similar challenges such as: unavailability of hourly historical demand data, electricity supply-demand gap, and varying electricity access rates in urban and rural areas in a country. National policies like lighting efficiency, electrification targets, transition to modern technologies and demand side management can be assessed using the proposed methodology. The accuracy of the developed model can be improved in future work by modelling the non-residential sectors (industry, services, commercial and transport) in each country separately as they all have different hourly electricity demand profiles.

\section{Acknowledgments}

The authors will like to acknowledge the Petroleum Technology Development Fund Nigeria (PTDF) for funding this research. The views in this study are those of the authors and do not necessarily reflect the views of PTDF. The authors will like to appreciate the WAPP information and coordination center for the data they provided. 


\section{Appendix A}

\begin{tabular}{|c|c|c|c|c|}
\hline \multirow[t]{3}{*}{ Country } & \multicolumn{4}{|c|}{ Electricity access rates $(\%)$} \\
\hline & \multicolumn{2}{|l|}{ Urban areas } & \multicolumn{2}{|l|}{ Rural areas } \\
\hline & Actual 2016 rates & Forecasted 2030 rates & Actual 2016 rates & Forecasted 2030 rates \\
\hline Benin & 70.8 & 54.1 & 18.0 & 47.0 \\
\hline Burkina Faso & 60.7 & 68.4 & 0.8 & 1.1 \\
\hline Cote d Ivoire & 92.0 & 100.0 & 38.0 & 40.0 \\
\hline Gambia & 69.0 & 70.5 & 16.0 & 17.5 \\
\hline Ghana & 90.0 & 98.0 & 67.0 & 100.0 \\
\hline Guinea & 82.2 & 100.0 & 6.9 & 14.7 \\
\hline Guinea Bissua & 29.8 & 31.6 & 4.0 & 5.3 \\
\hline Liberia & 34.0 & 26.0 & 1.3 & 2.0 \\
\hline Mali & 83.6 & 91.4 & 1.8 & 4.1 \\
\hline Niger & 65.4 & 78.8 & 4.7 & 6.8 \\
\hline Nigeria & 86.0 & 86.0 & 41.0 & 43.0 \\
\hline Senegal & 87.7 & 100.0 & 38.8 & 51.8 \\
\hline Sierra Leone & 47.0 & 50.0 & 2.5 & 3.6 \\
\hline Togo & 87.5 & 100.0 & 19.4 & 30.0 \\
\hline
\end{tabular}

Table A.1 Actual 2016 and forecasted 2030 electricity access rates of urban and rural areas in West African countries.

\begin{tabular}{|ll|}
\hline Country & Sources \\
\hline Benin & Demographic and health survey 2017 [55] \\
Burkina Faso & Social demographic characteristics survey 2016 [56] \\
& Malaria indicator survey 2014 [57] \\
Cote d Ivoire & Household lifecycle survey 2015 [58] \\
& Demographic and health survey and multiple indicator [59] \\
Gambia & Demographic and health survey 2014 [60] \\
Ghana & Malaria indicator survey 2016 [61] \\
& Ghana Living Standards Survey Round 6 [62] \\
Guinea & Multiple indicator cluster survey 2016 [63] \\
Guinea Bissua & Multiple indicator cluster survey 2014 [64] \\
Liberia & Household Income and Expenditure Survey 2016 [65] \\
& Malaria indicator survey 2016 [66] \\
Mali & Multiple indicator cluster survey 2015 [67] \\
& Malaria indicator survey 2015 [68] \\
Niger & National assessment study of socio-economic and demographic \\
Nigeria & indicators survey 2016 [69] \\
Senegal & Integrated surveys on agriculture and general households survey panel \\
Sierra Leone & 2016 [43] \\
Togo & Demographic and continuing health survey 2016 [70] \\
& Multiple indicator cluster survey 2017 [71] \\
& Malaria indicator survey 2017 [72] \\
\hline
\end{tabular}

Table A.2. Sources of demography input data used in the model

\begin{tabular}{|c|c|c|c|c|c|c|c|c|}
\hline & \multicolumn{4}{|l|}{ Urban areas } & \multicolumn{4}{|l|}{ Rural areas } \\
\hline Country & $\begin{array}{l}\text { Wage } \\
\text { employment } \\
(\%)\end{array}$ & $\begin{array}{l}\text { Non-farm } \\
\text { enterprise } \\
(\%)\end{array}$ & $\begin{array}{l}\text { Agriculture } \\
(\%)\end{array}$ & $\begin{array}{l}\text { Stay home all } \\
\text { day /retired } \\
(\%)\end{array}$ & $\begin{array}{l}\text { Wage } \\
\text { employment } \\
(\%)\end{array}$ & $\begin{array}{l}\text { Non-farm } \\
\text { enterprise } \\
(\%)\end{array}$ & $\begin{array}{l}\text { Agriculture } \\
(\%)\end{array}$ & $\begin{array}{l}\text { Stay home all } \\
\text { day /retired } \\
(\%)\end{array}$ \\
\hline Benin & 37.7 & 37.3 & 12.5 & 12.5 & 15.8 & 29.6 & 45.6 & 9.0 \\
\hline
\end{tabular}




\begin{tabular}{|l|l|l|l|l|l|l|l|l|}
\hline $\begin{array}{l}\text { Burkina } \\
\text { Faso }\end{array}$ & 32.6 & 41.8 & 6.2 & 19.4 & 1.5 & 48.3 & 25.3 & 24.9 \\
\hline $\begin{array}{l}\text { Cote d } \\
\text { Ivoire }\end{array}$ & 33.6 & 54.0 & 8.3 & 4.1 & 7.5 & 25.0 & 56.2 & 11.3 \\
\hline Gambia & 53.2 & 31.8 & 11.5 & 3.5 & 11.9 & 6.8 & 80.7 & 0.6 \\
\hline Ghana & 24.3 & 36.8 & 13.6 & 25.3 & 7.3 & 17.1 & 60.5 & 15.1 \\
\hline Guinea & 40.2 & 45.8 & 4.1 & 9.9 & 10.4 & 14.0 & 64.0 & 11.6 \\
\hline $\begin{array}{l}\text { Guinea } \\
\text { Bissua }\end{array}$ & 28.0 & 56.0 & 5.0 & 11.0 & 13.5 & 36.0 & 40.0 & 10.5 \\
\hline Liberia & 28.0 & 60.5 & 5.0 & 6.5 & 13.5 & 46.5 & 38.0 & 2.0 \\
\hline Mali & 37.8 & 44.8 & 5.0 & 12.4 & 5.2 & 26.7 & 60.0 & 8.1 \\
\hline Niger & 41.0 & 21.0 & 14.0 & 24.0 & 12.6 & 29.4 & 42.5 & 15.5 \\
\hline Nigeria & 10.5 & 54.5 & 8.4 & 26.6 & 3.4 & 18.1 & 42.5 & 36.0 \\
\hline Senegal & 42.0 & 31.3 & 8.1 & 18.6 & 22.0 & 15.0 & 50.0 & 13.0 \\
\hline $\begin{array}{l}\text { Sierra } \\
\text { Leone }\end{array}$ & 29.3 & 54.0 & 10.0 & 6.7 & 3.5 & 22.8 & 70.7 & 3.0 \\
\hline Togo & 39.0 & 50.0 & 3.0 & 8.0 & 17.9 & 20.0 & 53.4 & 8.7 \\
\hline
\end{tabular}

Table A.3. 2016 share of employment categories in urban and rural areas in West African countries.

\begin{tabular}{|l|l|l|l|}
\hline Appliances & $\begin{array}{l}\text { Urban household power } \\
\text { rating (Watts) }\end{array}$ & $\begin{array}{l}\text { Rural household power } \\
\text { rating (Watts) }\end{array}$ & Operating time \\
\hline $\begin{array}{l}\text { Audio-visual } \\
\text { Cooking }\end{array}$ & 125 & 200 & $7 \mathrm{hr} \pm 5 \mathrm{hr}$ \\
Computing & 2000 & 2200 & $2 \mathrm{hr} \pm 1 \mathrm{hr}$ \\
$\begin{array}{l}\text { Cloth dryers and washing } \\
\text { machines }\end{array}$ & 50 & 100 & $7 \mathrm{hr} \pm 5 \mathrm{hr}$ \\
Electric Iron & $2000 / 1200$ & $4000 / 3000$ & $2 \mathrm{hr} \pm 1 \mathrm{hr}$ consecutive \\
\hline
\end{tabular}

Table A.4 Assumed parameters for occupancy dependent appliances

\begin{tabular}{|l|l|}
\hline Speed selection $(\mathrm{k})$ & $\begin{array}{l}\text { Power consumption } \\
\text { (Watts) }\end{array}$ \\
\hline 1 & 42 \\
2 & 49 \\
3 & 56 \\
4 & 63 \\
\hline
\end{tabular}

Table A.5. Speed selection and power rating of modelled electric fan

\begin{tabular}{|lllllll|}
\hline Space & Sizes $\left(\mathrm{m}^{2}\right)$ & $\begin{array}{l}\text { Recommended } \\
\text { levels (Lux) }\end{array}$ & $\begin{array}{l}\text { lighting } \\
\text { Number in } 1 \text { Number in } 2 \\
\text { bedroom } \\
\text { households }\end{array}$ & $\begin{array}{l}\text { Number in } \\
\text { bedroom } \\
\text { households }\end{array}$ & $\begin{array}{l}\text { or } \\
\text { bedroom } \\
\text { households }\end{array}$ \\
\hline Living room & 20 & 100 & 1 & 1 & 1 \\
Dining room & 4.65 & 150 & 0 & 1 & 1 \\
Kitchen & 4.65 & 200 & 1 & 1 & 2 & 1 \\
Bedrooms & 9.3 & 100 & 1 & 1 & 2 \\
Bathroom & 4.2 & 100 & 0 & 0 & 1 \\
Toilet & 2.32 & 100 & 100 & 0 & 1 & \\
Storage & 1.5 & & & & 1 & 1 \\
\hline
\end{tabular}

Table A.6. Sizes, numbers and illumination levels of spaces in households 


\begin{tabular}{|c|c|c|c|c|c|c|c|c|}
\hline \multirow[b]{2}{*}{ Country } & \multicolumn{4}{|c|}{ Urban households } & \multicolumn{4}{|c|}{ Rural households } \\
\hline & $\begin{array}{l}\text { Fluorescent } \\
\text { lamps (\%) }\end{array}$ & $\begin{array}{l}\text { Incandesc } \\
\text { ent lamps } \\
(\%)\end{array}$ & $\begin{array}{l}\text { CFL lamps } \\
(\%)\end{array}$ & $\begin{array}{l}\text { LED lamps } \\
(\%)\end{array}$ & $\begin{array}{l}\text { Fluorescent } \\
\text { lamps (\%) }\end{array}$ & $\begin{array}{l}\text { Incandesc } \\
\text { ent lamps } \\
(\%)\end{array}$ & $\begin{array}{l}\text { CFL lamps } \\
(\%)\end{array}$ & $\begin{array}{ll}\text { LED lamps } \\
(\%)\end{array}$ \\
\hline Benin & 20 & 30 & 40 & 10 & 5 & 40 & 45 & 10 \\
\hline $\begin{array}{l}\text { Burkina } \\
\text { Faso }\end{array}$ & 20 & 30 & 40 & 10 & 5 & 40 & 45 & 10 \\
\hline $\begin{array}{l}\text { Cote d } \\
\text { Ivoire }\end{array}$ & 15 & 20 & 40 & 25 & 32 & 45 & 21 & 2 \\
\hline Gambia & 20 & 40 & 30 & 10 & 5 & 60 & 25 & 10 \\
\hline Ghana & 2 & 0 & 90 & 8 & 2 & 0 & 96 & 2 \\
\hline Guinea & 20 & 30 & 40 & 10 & 5 & 40 & 45 & 10 \\
\hline $\begin{array}{l}\text { Guinea } \\
\text { Bissua }\end{array}$ & 20 & 30 & 40 & 10 & 5 & 40 & 45 & 10 \\
\hline Liberia & 20 & 40 & 30 & 10 & 5 & 60 & 25 & 10 \\
\hline Mali & 20 & 30 & 40 & 10 & 5 & 40 & 45 & 10 \\
\hline Niger & 20 & 30 & 40 & 10 & 5 & 40 & 45 & 10 \\
\hline Nigeria & 6 & 10 & 50 & 34 & 10 & 30 & 40 & 20 \\
\hline Senegal & 20 & 20 & 50 & 10 & 5 & 20 & 65 & 10 \\
\hline $\begin{array}{l}\text { Sierra } \\
\text { Leone }\end{array}$ & 20 & 25 & 30 & 25 & 20 & 35 & 25 & 10 \\
\hline Togo & 20 & 30 & 40 & 10 & 5 & 40 & 45 & 10 \\
\hline
\end{tabular}

Table A.7. 2016 assumed ownership rate for lighting bulbs in urban and rural households.

\begin{tabular}{|c|c|c|c|c|c|c|c|c|c|}
\hline \multicolumn{4}{|c|}{ Benin } & \multicolumn{3}{|c|}{ Burkina Faso } & \multicolumn{3}{|c|}{ Cote d Ivoire } \\
\hline Year & $\begin{array}{l}\text { Actual } \\
\text { demand } \\
(\mathrm{GWh})\end{array}$ & $\begin{array}{l}\text { Forecasted } \\
\text { demand } \\
(\mathrm{GWh})\end{array}$ & $\begin{array}{l}\text { Relative } \\
\text { error }(\%)\end{array}$ & $\begin{array}{l}\text { Actual } \\
\text { demand } \\
(\mathrm{GWh})\end{array}$ & $\begin{array}{l}\text { Forecasted } \\
\text { demand } \\
(\mathrm{GWh})\end{array}$ & $\begin{array}{l}\text { Relative } \\
\text { error } \\
(\%) \\
\end{array}$ & $\begin{array}{l}\text { Actual } \\
\text { demand } \\
(\mathrm{GWh})\end{array}$ & $\begin{array}{l}\text { Forecasted } \\
\text { demand } \\
(\mathrm{GWh})\end{array}$ & $\begin{array}{l}\text { Relative } \\
\text { error } \\
(\%) \\
\end{array}$ \\
\hline 2013 & 580 & 569 & $-2 \%$ & 612 & 581 & $-5 \%$ & 2292 & 2240 & $-2 \%$ \\
\hline 2014 & 578 & 600 & $4 \%$ & 651 & 611 & $-6 \%$ & 2670 & 2441 & $-9 \%$ \\
\hline 2015 & 672 & 629 & $-7 \%$ & 687 & 637 & $-7 \%$ & 2721 & 2657 & $-2 \%$ \\
\hline \multicolumn{4}{|c|}{ Gambia } & \multicolumn{3}{|c|}{ Ghana } & \multicolumn{3}{|c|}{ Guinea } \\
\hline Year & $\begin{array}{l}\text { Actual } \\
\text { demand } \\
(G W h)\end{array}$ & $\begin{array}{l}\text { Forecasted } \\
\text { demand } \\
(\mathrm{GWh})\end{array}$ & $\begin{array}{l}\text { Relative } \\
\text { error } \\
(\%)\end{array}$ & $\begin{array}{l}\text { Actual } \\
\text { demand } \\
(\mathrm{GWh})\end{array}$ & $\begin{array}{l}\text { Forecasted } \\
\text { demand } \\
(\mathrm{GWh})\end{array}$ & $\begin{array}{l}\text { Relative } \\
\text { error } \\
(\%)\end{array}$ & $\begin{array}{l}\text { Actual } \\
\text { demand } \\
(G W h)\end{array}$ & $\begin{array}{l}\text { Forecasted } \\
\text { demand } \\
(\mathrm{GWh})\end{array}$ & $\begin{array}{l}\text { Relative } \\
\text { error } \\
(\%)\end{array}$ \\
\hline 2013 & 131 & 146 & $11 \%$ & 6099 & 6308 & $3 \%$ & 358 & 402 & $12 \%$ \\
\hline 2014 & 135 & 152 & $13 \%$ & 6145 & 6501 & $6 \%$ & 366 & 409 & $12 \%$ \\
\hline 2015 & 134 & 154 & $15 \%$ & 6210 & 6694 & $8 \%$ & 372 & 421 & $13 \%$ \\
\hline \multicolumn{4}{|c|}{ Guinea Bissua } & \multicolumn{3}{|c|}{ Liberia } & \multicolumn{3}{|c|}{ Mali } \\
\hline Year & $\begin{array}{l}\text { Actual } \\
\text { demand } \\
(\mathrm{GWh})\end{array}$ & $\begin{array}{l}\text { Forecasted } \\
\text { demand } \\
(G W h)\end{array}$ & $\begin{array}{l}\text { Relative } \\
\text { error } \\
(\%)\end{array}$ & $\begin{array}{l}\text { Actual } \\
\text { demand } \\
(\mathrm{GWh})\end{array}$ & $\begin{array}{l}\text { Forecasted } \\
\text { demand } \\
(\mathrm{GWh})\end{array}$ & $\begin{array}{l}\text { Relative } \\
\text { error } \\
(\%)\end{array}$ & $\begin{array}{l}\begin{array}{l}\text { Actual } \\
\text { demand } \\
(G W h)\end{array} \\
\end{array}$ & $\begin{array}{l}\text { Forecasted } \\
\text { demand } \\
(\mathrm{GWh})\end{array}$ & $\begin{array}{l}\text { Relative } \\
\text { error } \\
(\%)\end{array}$ \\
\hline 2013 & 16 & 14 & $-13 \%$ & 137 & 145 & $6 \%$ & 744 & 809 & $9 \%$ \\
\hline 2014 & 15 & 13 & $-11 \%$ & 137 & 152 & $11 \%$ & 832 & 831 & $0 \%$ \\
\hline 2015 & 16 & 14 & $-13 \%$ & 138 & 158 & $15 \%$ & 840 & 855 & $2 \%$ \\
\hline \multicolumn{4}{|c|}{ Niger } & \multicolumn{3}{|c|}{ Nigeria } & \multicolumn{3}{|c|}{ Senegal } \\
\hline Year & $\begin{array}{l}\text { Actual } \\
\text { demand } \\
(\mathrm{GWh})\end{array}$ & $\begin{array}{l}\text { Forecasted } \\
\text { demand } \\
(\mathrm{GWh})\end{array}$ & $\begin{array}{l}\text { Relative } \\
\text { error } \\
(\%)\end{array}$ & $\begin{array}{l}\text { Actual } \\
\text { demand } \\
(\mathrm{GWh})\end{array}$ & $\begin{array}{l}\text { Forecasted } \\
\text { demand } \\
(\mathrm{GWh})\end{array}$ & $\begin{array}{l}\text { Relative } \\
\text { error } \\
(\%)\end{array}$ & $\begin{array}{l}\begin{array}{l}\text { Actual } \\
\text { demand } \\
(G W h)\end{array} \\
\end{array}$ & $\begin{array}{l}\text { Forecasted } \\
\text { demand } \\
(\mathrm{GWh})\end{array}$ & $\begin{array}{l}\text { Relative } \\
\text { error } \\
(\%)\end{array}$ \\
\hline 2013 & 347 & 365 & $5 \%$ & 10029 & 10609 & $6 \%$ & 1818 & 1667 & $-8 \%$ \\
\hline
\end{tabular}




\begin{tabular}{|c|c|c|c|c|c|c|c|c|c|}
\hline 2014 & 383 & 404 & $5 \%$ & 10436 & 11226 & $8 \%$ & 1896 & 1730 & $-9 \%$ \\
\hline 2015 & 429 & 426 & $-1 \%$ & 10713 & 11442 & $7 \%$ & 1943 & 1870 & $-4 \%$ \\
\hline \multicolumn{5}{|c|}{ Sierra Leone } & \multicolumn{2}{|l|}{ Togo } & & & \\
\hline Year & $\begin{array}{l}\text { Actual } \\
\text { demand } \\
(\mathrm{GWh})\end{array}$ & $\begin{array}{l}\text { Forecasted } \\
\text { demand } \\
(\mathrm{GWh})\end{array}$ & $\begin{array}{l}\text { Relative } \\
\text { error } \\
(\%)\end{array}$ & $\begin{array}{l}\text { Actual } \\
\text { demand } \\
(\mathrm{GWh})\end{array}$ & $\begin{array}{l}\text { Forecasted } \\
\text { demand } \\
(\mathrm{GWh})\end{array}$ & $\begin{array}{l}\text { Relative } \\
\text { error } \\
(\%)\end{array}$ & & & \\
\hline 2013 & 73 & 130 & $79 \%$ & 446 & 383 & $-14 \%$ & & & \\
\hline 2014 & 80 & 131 & $64 \%$ & 494 & 421 & $-15 \%$ & & & \\
\hline 2015 & 78 & 66 & $-15 \%$ & 546 & 471 & $-14 \%$ & & & \\
\hline
\end{tabular}

Table A.8. Validation test showing the actual and forecasted non-residential electricity demand data for West African countries between 2013-2015

\begin{tabular}{|c|c|c|c|c|c|c|c|c|}
\hline & \multicolumn{4}{|c|}{ Urban households } & \multicolumn{4}{|c|}{ Rural households } \\
\hline Country & $\begin{array}{l}\text { Fluorescent } \\
\text { lamps }(\%)\end{array}$ & $\begin{array}{l}\text { Incandesc } \\
\text { ent lamps } \\
(\%)\end{array}$ & $\begin{array}{l}\text { CFL lamps } \\
(\%)\end{array}$ & $\begin{array}{l}\text { LED lamps } \\
(\%)\end{array}$ & $\begin{array}{l}\text { Fluorescent } \\
\text { lamps }(\%)\end{array}$ & $\begin{array}{l}\text { Incandesc } \\
\text { ent lamps } \\
(\%)\end{array}$ & $\begin{array}{l}\text { CFL lamps } \\
(\%)\end{array}$ & $\begin{array}{l}\text { LED lamps } \\
(\%)\end{array}$ \\
\hline Benin & 0 & 0 & 70 & 30 & 0 & 0 & 60 & 40 \\
\hline $\begin{array}{l}\text { Burkina } \\
\text { Faso }\end{array}$ & 0 & 0 & 70 & 30 & 0 & 0 & 60 & 40 \\
\hline $\begin{array}{l}\text { Cote d } \\
\text { Ivoire }\end{array}$ & 10 & 5 & 55 & 30 & 20 & 10 & 60 & 10 \\
\hline Gambia & 0 & 0 & 70 & 30 & 0 & 0 & 60 & 40 \\
\hline Ghana & 0 & 0 & 90 & 10 & 0 & 0 & 95 & 5 \\
\hline Guinea & 0 & 0 & 70 & 30 & 0 & 0 & 60 & 40 \\
\hline $\begin{array}{l}\text { Guinea } \\
\text { Bissua }\end{array}$ & 0 & 0 & 70 & 30 & 0 & 0 & 60 & 40 \\
\hline Liberia & 0 & 0 & 70 & 30 & 0 & 0 & 60 & 40 \\
\hline Mali & 0 & 0 & 70 & 30 & 0 & 0 & 60 & 40 \\
\hline Niger & 0 & 0 & 70 & 30 & 0 & 0 & 60 & 40 \\
\hline Nigeria & 6 & 0 & 50 & 44 & 10 & 5 & 40 & 45 \\
\hline Senegal & 0 & 0 & 70 & 30 & 0 & 0 & 60 & 40 \\
\hline $\begin{array}{l}\text { Sierra } \\
\text { Leone }\end{array}$ & 20 & 0 & 50 & 30 & 20 & 0 & 50 & 30 \\
\hline Togo & 0 & 0 & 70 & 30 & 0 & 0 & 60 & 40 \\
\hline
\end{tabular}

Table A.9. 2030 assumed ownership rate for lighting bulbs in urban and rural households.

\begin{tabular}{|llll|}
\hline Country & $\begin{array}{l}\text { Actual 2016 annual } \\
\text { demand (GWh) }\end{array}$ & $\begin{array}{l}\text { WAPP master plan } \\
2016 \text { annual demand } \\
(\mathrm{GWh})\end{array}$ & $\begin{array}{l}\text { Modelled 2016 } \\
\text { annual demand } \\
(\mathrm{GWh})\end{array}$ \\
\hline Benin & 1302 & 1968 & 1217 \\
Burkina Faso & 1370 & 1265 & 1303 \\
Cote d Ivoire & 5900 & 8197 & 6760 \\
Gambia & 250 & 747 & 241 \\
Ghana & 13081 & 15223 & 11794 \\
Guinea & 1031 & 1718 & 1071 \\
Guinea Bissua & 35 & 187 & 44 \\
Liberia & 242 & 279 & 251 \\
Mali & 1766 & 2898 & 1845 \\
Niger & 1124 & 1306 & 993 \\
Nigeria & 23947 & 72926 & 25202 \\
Senegal & 3007 & 4311 & 3194 \\
Sierra Leone & 200 & 715 & 212
\end{tabular}


Table A.10. 2016 actual, modelled and WAPP master plan electricity demand levels.
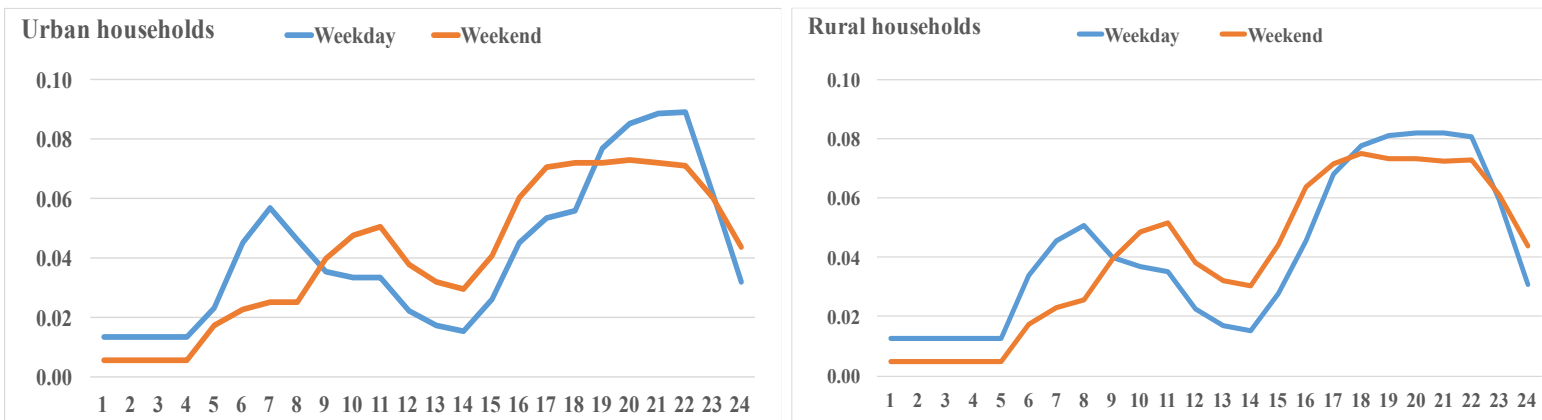

Figure A.1. Probability of use of cloth dryers and washing machines in urban and rural households in Nigeria.
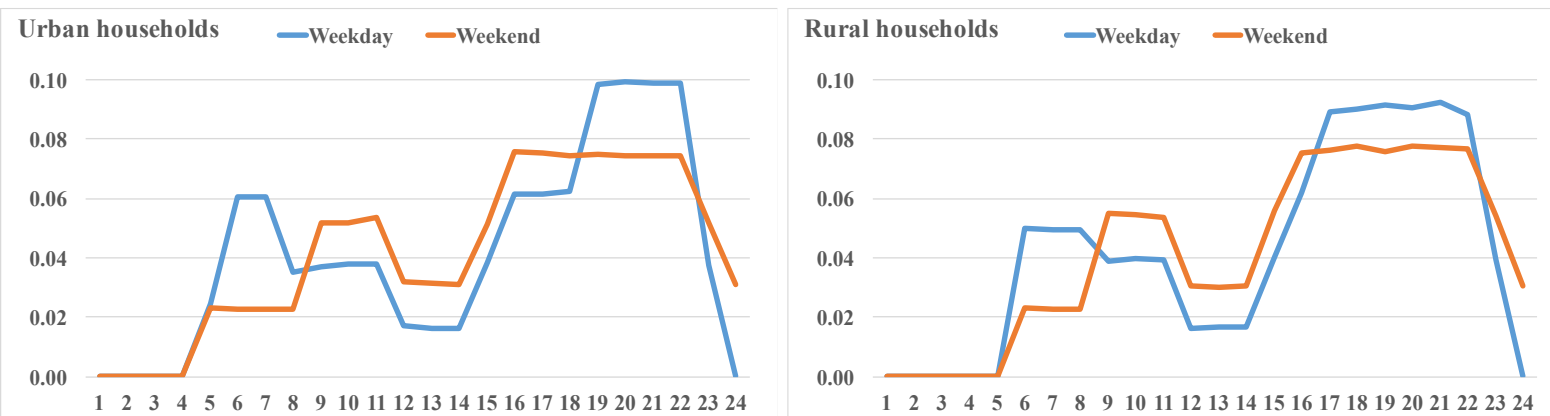

Figure A.2. Probability of use of electric irons in urban and rural households in Nigeria

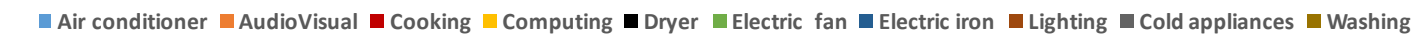
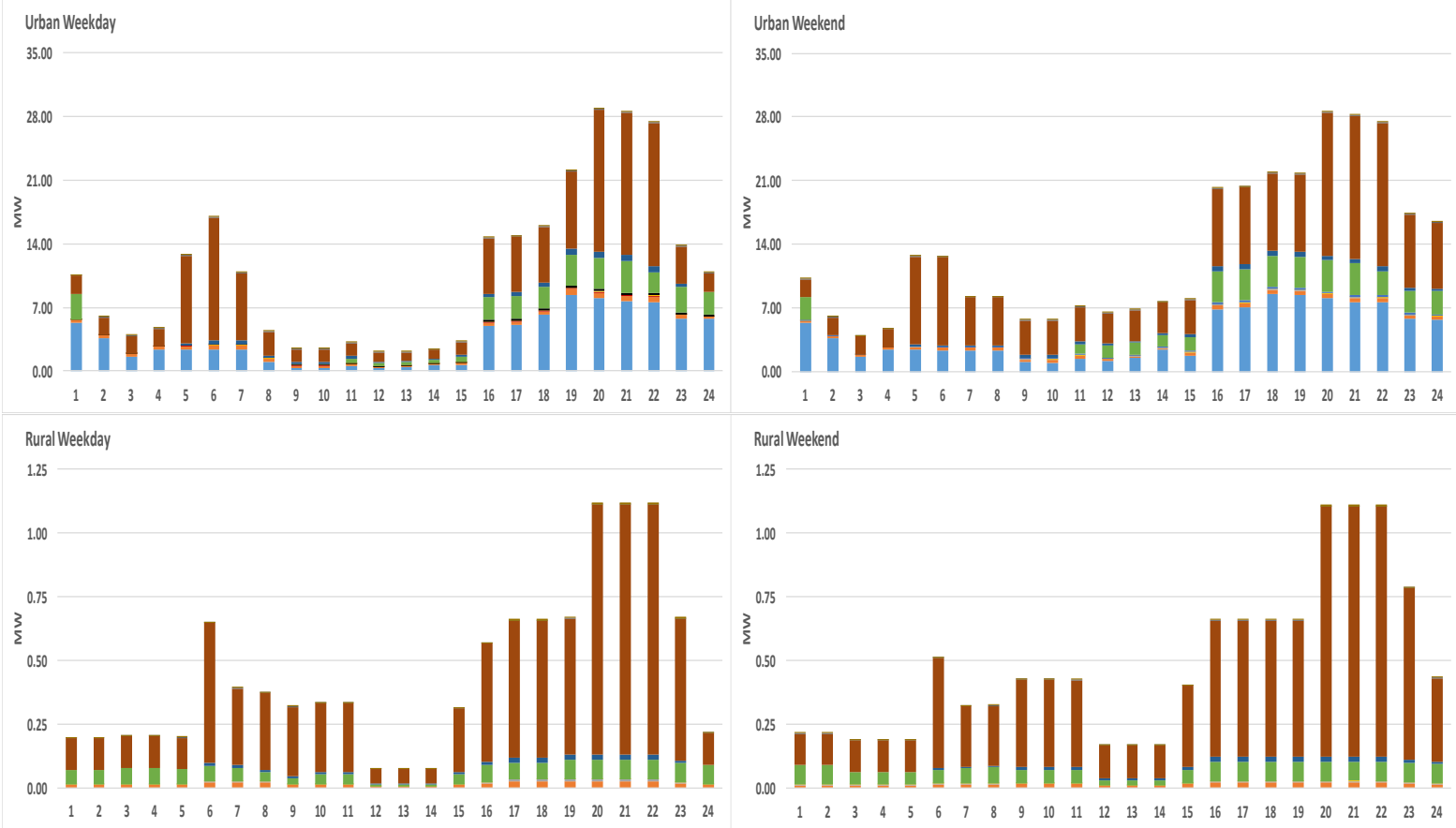
Figure A.3. Weekday ( $5^{\text {th }}$ April 2030) and weekend (6 $6^{\text {th }}$ April 2030) simulated residential electricity demand profiles in Guinea Bissau's urban and rural households

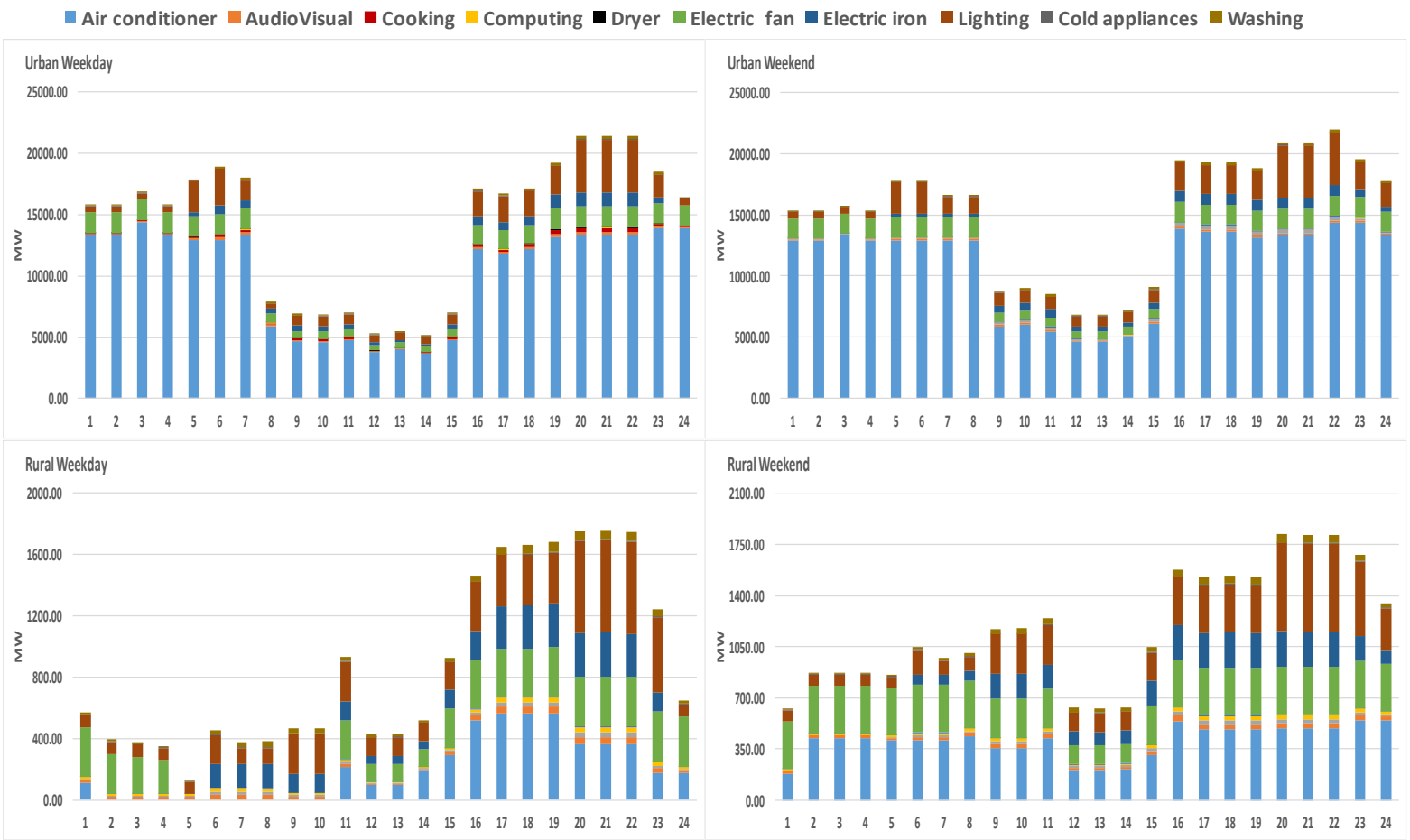

Figure A.4. Weekday (5 $5^{\text {th }}$ April 2030) and weekend (6 ${ }^{\text {th }}$ April 2030) simulated residential electricity demand profiles in Nigeria's urban and rural households

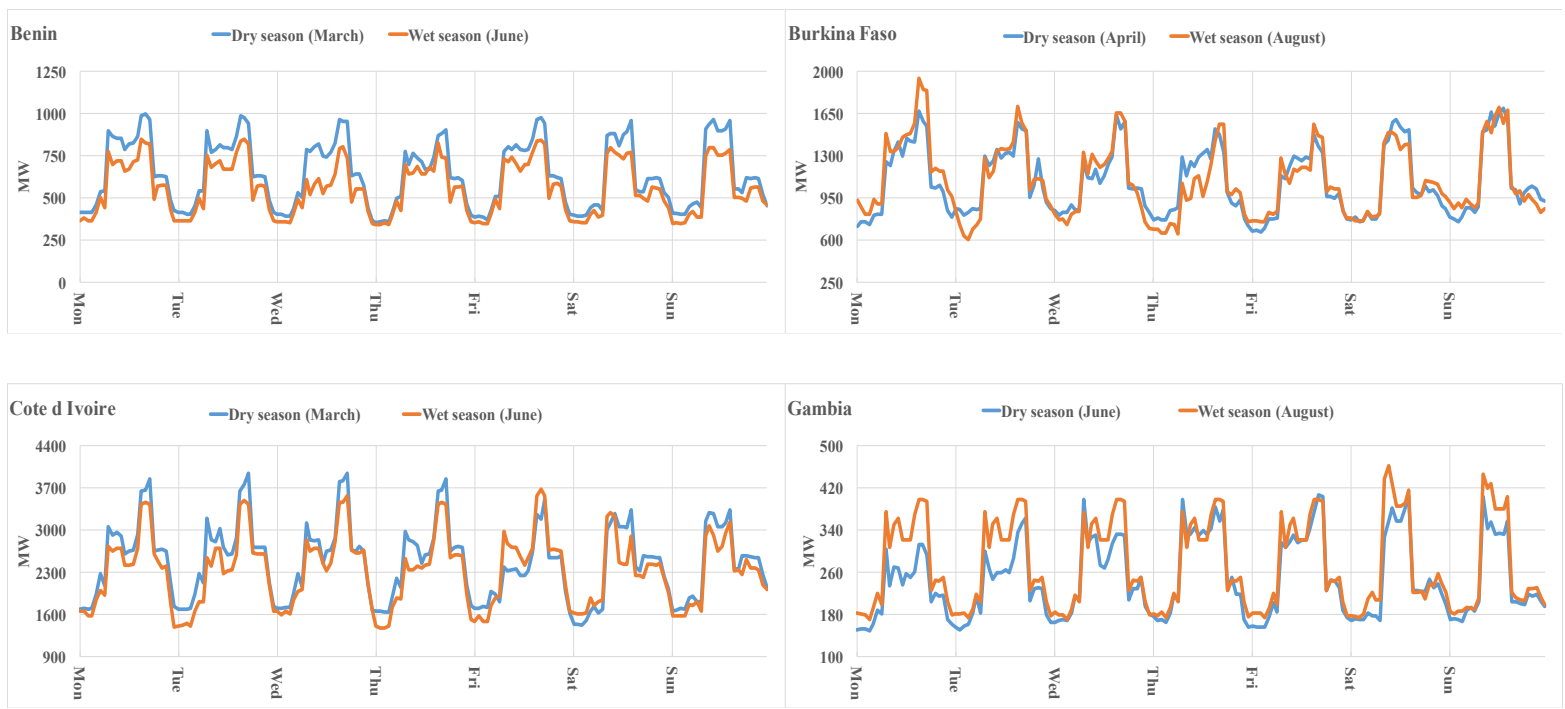




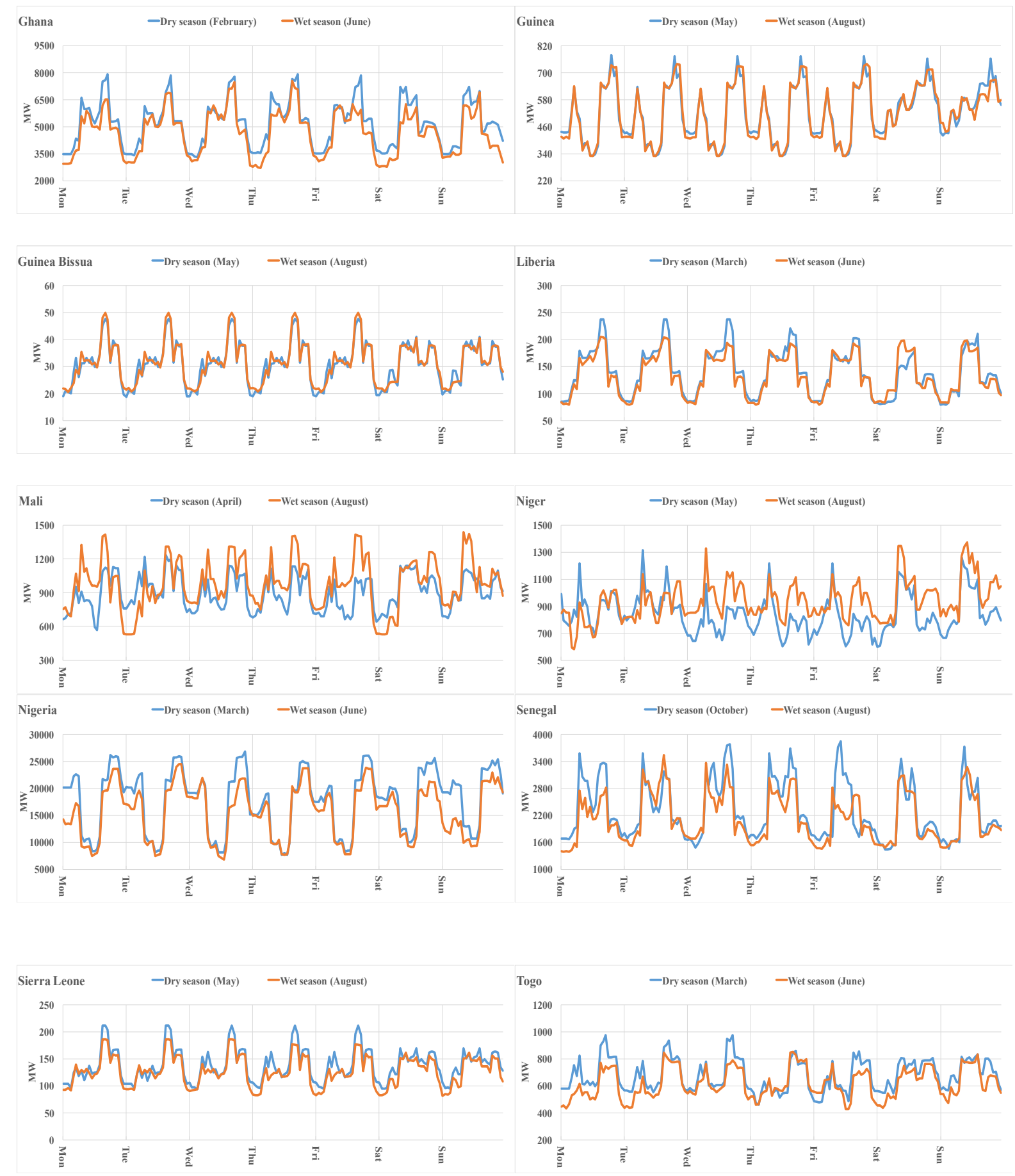

Figure A.5. 2030 Hourly demand profiles of representative weeks in dry and wet seasons.

$\omega_{s}=\cos ^{-1}(-\tan \phi \tan \delta)$

$\left.\delta=23.45 \times \sin \left(\frac{360}{365}\right) \times(d+284)\right)$

(A.2)

$T_{S S}=\left(\frac{\omega_{S}}{15}+12\right)+T_{Z}$ 
$D_{L}=\frac{2 \omega_{s}}{15}$

$T_{S R}=T_{S S}-D_{L}$

Where $\omega_{s}$ is the sunset hour angle, $\phi$ is the country's latitude, and $\delta$ is the sun's daily declination angle. $d$ is the day of the year, where January $1^{\text {st }}$ is 1 and December $25^{\text {th }}$ is 366 . $T_{Z}$ is the country's time zone and $D_{L}$ is the length of day. $T_{S S}$ and $T_{S R}$ are the sunset and sunrise time respectively.

\section{References}

[1] World Bank. World Bank Open Data 2016. http://data.worldbank.org (accessed March 1, 2018).

[2] Masami K, Trimble C. Making Power Affordable for Africa and Viable for Its Utilities. Washington, DC, United States: The World Bank; 2016. doi:https://doi.org/10.1596/25091.

[3] West African Power Pool. 2016 - 2019 WAPP Business Plan 2015. http://www.ecowapp.org/sites/default/files/2015-2019_business_plan.pdf (accessed March 15, 2016).

[4] ECREEE. ECOWAS renewable energy policy 2015.

[5] Bhattacharyya SC, Timilsina G. R. Energy demand models for policy formulation: a comparative study of energy demand models. The World Bank; 2009.

[6] Taliotis C, Bazilian M, Welsch M, Gielen D, Howells M. Grand Inga to power Africa: Hydropower development scenarios to 2035. Energy Strateg Rev 2014;4:1-10. doi:10.1016/j.esr.2014.01.001.

[7] Bazilian M, Nussbaumer P, Rogner HH, Brew-Hammond A, Foster V, Pachauri S, Williams E, Howells M, Niyongabo P, Musaba L, Gallachóir B, Radka M, Kammen D. Energy access scenarios to 2030 for the power sector in sub-Saharan Africa. Util PolicyPolicy 2012. doi:10.1016/j.jup.2011.11.002.

[8] Taliotis C, Shivakumar A, Ramos E, Howells M, Mentis D, Sridharan, Broad O, Mofor L. An indicative analysis of investment opportunities in the African electricity supply sector - Using TEMBA (The Electricity Model Base for Africa). Energy Sustain Dev 2016;31:50-66. doi:10.1016/j.esd.2015.12.001.

[9] Gnansounou E, Bayem H, Bednyagin D, Dong J. Strategies for regional integration of electricity supply in West Africa. Energy Policy 2007;35:4142-53. doi:10.1016/j.enpol.2007.02.023.

[10] Mentis D, Howells M, Rogner H, Korkovelos A, Arderne C. Lighting the World : the first application of an open source, spatial electrification tool (OnSSET ) on SubSaharan Africa Lighting the World : the first application of an open source, spatial electrification tool ( OnSSET ) on Sub-Saharan Africa 2017.

[11] Sanoh A, Kocaman AS, Kocal S, Sherpa S, Modi V. The economics of clean energy resource development and grid interconnection in Africa. Renew Energy 2014;62:598609. doi:10.1016/j.renene.2013.08.017.

[12] West African Power Pool. Update of the ECOWAS Revised Master Plan for the Generation and Transmission of Electrical Energy: Final Report Volume 1: Study Data 2011. http://www.ecowapp.org/sites/default/files/mp_wapp_volume_1.pdf (accessed March 15, 2016).

[13] Rosnes O, Vennemo H. The cost of providing electricity to Africa. Energy Econ 
2012;34:1318-28. doi:10.1016/j.eneco.2012.06.008.

[14] Suganthi L, Samuel AA. Energy models for demand forecasting - A review. Renew Sustain Energy Rev 2012;16:1223-40. doi:10.1016/j.rser.2011.08.014.

[15] Bhattacharyya SC, Timilsina GR. Modelling energy demand of developing countries: Are the specific features adequately captured? Energy Policy 2010;38:1979-90. doi:10.1016/j.enpol.2009.11.079.

[16] Shimoda Y, Fujii T, Morikawa T, Mizuno M. Residential end-use energy simulation at city scale. Build Environ 2004;39:959-67. doi:10.1016/j.buildenv.2004.01.020.

[17] Yao R, Steemers K. A method of formulating energy load profile for domestic buildings in the UK. Energy Build 2005;37:663-71. doi:10.1016/j.enbuild.2004.09.007.

[18] Paatero J V., Lund PD. A model for generating household electricity load profiles. Int J Energy Res 2006;30:273-90. doi:10.1002/er.1136.

[19] Soares LJ, Medeiros MC. Modeling and forecasting short-term electricity load: A comparison of methods with an application to Brazilian data. Int J Forecast 2008;24:630-44. doi:10.1016/j.ijforecast.2008.08.003.

[20] Widén J, Wäckelgård E. A high-resolution stochastic model of domestic activity patterns and electricity demand. Appl Energy 2010;87:1880-92. doi:10.1016/j.apenergy.2009.11.006.

[21] Ren Z, Foliente G, Chan WY, Chen D, Ambrose M, Paevere P. A model for predicting household end-use energy consumption and greenhouse gas emissions in Australia. Int J Sustain Build Technol Urban Dev 2013;4:210-28.

doi:10.1080/2093761X.2013.801801.

[22] Muratori M, Roberts MC, Sioshansi R, Marano V, Rizzoni G. A highly resolved modeling technique to simulate residential power demand. Appl Energy 2013;107:465-73. doi:10.1016/j.apenergy.2013.02.057.

[23] Fischer D, Härtl A, Wille-Haussmann B. Model for electric load profiles with high time resolution for German households. Energy Build 2015;92:170-9. doi:10.1016/j.enbuild.2015.01.058.

[24] Andersen FM, Baldini M, Hansen LG, Jensen CL. Households' hourly electricity consumption and peak demand in Denmark. Appl Energy 2017;208:607-19. doi:10.1016/j.apenergy.2017.09.094.

[25] Sandels C, Widén J, Nordström L. Forecasting household consumer electricity load profiles with a combined physical and behavioral approach. Appl Energy 2014;131:267-78. doi:10.1016/j.apenergy.2014.06.048.

[26] Aman S, Ping H. Modelling and forecasting electricity consumption of Malaysian large steel mills. Sci Res 2011;6:1817-30. doi:10.5897/SRE10.884.

[27] Pielow A, Sioshansi R, Roberts MC. Modeling short-run electricity demand with longterm growth rates and consumer price elasticity in commercial and industrial sectors. Energy 2012;46:533-40. doi:10.1016/j.energy.2012.07.059.

[28] Sadri A, Ardehali MM, Amirnekooei K. General procedure for long-term energyenvironmental planning for transportation sector of developing countries with limited data based on LEAP (long-range energy alternative planning) and EnergyPLAN. Energy 2014;77:831-43. doi:10.1016/j.energy.2014.09.067.

[29] Voulis N, Warnier M, Brazier FMT. Impact of Service Sector Loads on Renewable Resource Integration 2016;205:1311-26. doi:10.1016/j.apenergy.2017.07.134.

[30] Kipping A, Trømborg E. Modeling hourly consumption of electricity and district heat in non-residential buildings. Energy 2017;123:473-86. doi:10.1016/j.energy.2017.01.108.

[31] Hainoun A. Construction of the hourly load curves and detecting the annual peak load 
of future Syrian electric power demand using bottom-up approach. Int J Electr Power Energy Syst 2009;31:1-12. doi:10.1016/j.ijepes.2008.09.006.

[32] Pina A, Silva C, Ferrão P. Modeling hourly electricity dynamics for policy making in long-term scenarios. Energy Policy 2011;39:4692-702.

doi:10.1016/j.enpol.2011.06.062.

[33] Andersen FM, Larsen H V., Boomsma TK. Long-term forecasting of hourly electricity load: Identification of consumption profiles and segmentation of customers. Energy Convers Manag 2013;68:244-52. doi:10.1016/j.enconman.2013.01.018.

[34] Spataru C, Barrett M. DEAM: A Scalable Dynamic Energy Agents Model for Demand and Supply, 2015, p. 195-200. doi:10.1109/UKSim.2015.103.

[35] Boßmann T, Staffell I. The shape of future electricity demand: Exploring load curves in 2050s Germany and Britain. Energy 2015;90:1317-33. doi:10.1016/j.energy.2015.06.082.

[36] Yukseltan E, Yucekaya A, Bilge AH. Forecasting electricity demand for Turkey: Modeling periodic variations and demand segregation. Appl Energy 2017;193:287-96. doi:10.1016/j.apenergy.2017.02.054.

[37] Miketa A, Merven B. West African Power Pool: Planning and Prospects for Renewable Energy. Abu Dhabi: International Renewable Energy Agency (IRENA); 2013.

[38] Adeoye O, Spataru C. Sustainable development of the West African Power Pool: Increasing solar energy integration and regional electricity trade. Energy Sustain Dev 2018;45:124-34. doi:https://doi.org/10.1016/j.esd.2018.05.007.

[39] Ouedraogo NS. Modeling sustainable long-term electricity supply-demand in Africa. Appl Energy 2017;190:1047-67. doi:10.1016/j.apenergy.2016.12.162.

[40] The MathWorks I. MATLAB and Statistics Toolbox Release $2017 \mathrm{~b} 2017$.

[41] Swan LG, Ugursal VI. Modeling of end-use energy consumption in the residential sector: A review of modeling techniques. Renew Sustain Energy Rev 2009;13:181935. doi:10.1016/j.rser.2008.09.033.

[42] Grandjean A, Adnot J, Binet G. A review and an analysis of the residential electric load curve models. Renew Sustain Energy Rev 2012;16:6539-65. doi:10.1016/j.rser.2012.08.013.

[43] National Bureau of Statistics. Integrated Surveys on Agriculture General Household Survey Panel 2015/2016. Abuja, Nigeria: National Bureau of Statistics Nigeria; 2016.

[44] Richardson I, Thomson M, Infield D. A high-resolution domestic building occupancy model for energy demand simulations. Energy Build 2008;40:1560-6. doi:10.1016/j.enbuild.2008.02.006.

[45] Muratori M, Roberts MC, Sioshansi R, Marano V, Rizzoni G. A highly resolved modeling technique to simulate residential power demand. Appl Energy 2013;107:465-73. doi:10.1016/j.apenergy.2013.02.057.

[46] Gruber JK, Jahromizadeh S, Prodanović M, Rakočević V. Application-oriented modelling of domestic energy demand. Int J Electr Power Energy Syst 2014;61:65664. doi:10.1016/j.ijepes.2014.04.008.

[47] The Weather Company. Weather Undeground 2016. https://www.wunderground.com (accessed June 1, 2018).

[48] ASHRAE. Standard 55-2010, Thermal Environmental Conditions for Human Occupancy. Atlanta: American Society of Heating, Refrigerating, and AirConditioning Engineers. ASHRAE Inc 2010;2010:42. doi:ISSN 1041-2336.

[49] National Building Code. Nigeria: LexisNexis Group; 2006.

[50] U.S. Energy Information Administration. International 2018. https://www.eia.gov/beta/international/ (accessed March 4, 2018). 
[51] International Energy Agency. Statistics 2018. https://www.iea.org/classicstats/statisticssearch/ (accessed March 4, 2018).

[52] United Nations. World Urbanization Prospects 20182018. https://population.un.org/wup/ (accessed February 3, 2018).

[53] International Monetary Fund. World Economic Outlook 2018. https://www.imf.org/external/datamapper/datasets/WEO (accessed June 20, 2018).

[54] WAPP- Information and Coordination Centre. Monthly Operations Report. Benin: West African Power Pool; 2016.

[55] Institute of the Statistics and the Economic Analysis. Demographic and health survey 2017-2018. Cotonou, Benin: 2017.

[56] The National Institute of Statistics and Demography. Social demographic characteristics survey. Ouagadougou, Burkina Faso: 2016.

[57] The National Institute of Statistics and Demography. Malaria indicator survey. Ouagadougou, Burkina Faso: 2014.

[58] National Institute of Statistics. Household lifecycle survey. Abidjan, Cote D Ivoire: 2015.

[59] National Institute of Statistics. Demographic and health survey and multiple Indicator. Abidjan, Cote D Ivoire: 2012.

[60] Gambia Bureau of Statistics. Demographic and health survey. Banjul, Gambia: 2014.

[61] Ghana Statistical Service. Malaria indicator survey. Accra, Ghana: 2016.

[62] Ghana Statistical Service. Ghana Living Standards Survey Round 6. Accra, Ghana: 2014.

[63] National Institute of Statistics Guinea. Multiple indicator cluster survey 2016. Conakry, Guinee: 2016.

[64] National Statistical Office. Multiple indicator cluster survey 2014. Guine Bissau: 2014.

[65] Liberia Institute of Statistics and Geo Information Services. Household Income and Expenditure Survey 2016. Monrovia, Liberia: 2016.

[66] Liberia Institute of Statistics and Geo Information Services. Malaria indicator survey. Monrovia, Liberia: 2016.

[67] National Institute of Statistics. Multiple indicator cluster survey. Bamako, Mali: 2015.

[68] National Institute of Statistics. Malaria indicator survey. Bamako, Mali: 2015.

[69] National Institute of Statistics Niger. National assessment study of socio-economic and demographic indicators. Niger: 2016.

[70] National Agency of Statistics and Demography. Demographic and continuing health survey. Dakar, Senegal: 2017.

[71] Statistics Sierra Leone. Multiple indicator cluster survey 2017. Freetown, Sierra Leone: 2018.

[72] National Institute of Statistics and Economic and Demographic Studies. Malaria indicator survey 2017. Lome, Togo: 2018. 